\title{
Targeted mutation of mouse skeletal muscle sodium channel produces myotonia and potassium-sensitive weakness
}

\author{
Lawrence J. Hayward, ${ }^{1}$ Joanna S. Kim, ${ }^{2}$ Ming-Yang Lee, ${ }^{1}$ Hongru Zhou, ${ }^{1}$ Ji W. Kim, ${ }^{2}$ \\ Kumudini Misra, ${ }^{1}$ Mohammad Salajegheh, ${ }^{1}$ Fen-fen Wu, ${ }^{3}$ Chie Matsuda, ${ }^{2}$ Valerie Reid, ${ }^{2}$ \\ Didier Cros, ${ }^{2}$ Eric P. Hoffman, ${ }^{4}$ Jean-Marc Renaud, ${ }^{5}$ Stephen C. Cannon, ${ }^{3}$ and Robert H. Brown Jr. ${ }^{2}$ \\ 1Department of Neurology, University of Massachusetts Medical School, Worcester, Massachusetts, USA. ${ }^{2}$ Department of Neurology, Massachusetts General \\ Hospital, Boston, Massachusetts, USA. ${ }^{3}$ Department of Neurology, University of Texas Southwestern Medical Center, Dallas, Texas, USA. ${ }^{4}$ Microarray Center, \\ Children's National Medical Center, Washington, D.C., USA. ${ }^{5}$ Department of Cellular and Molecular Medicine, University of Ottawa, Ottawa, Ontario, Canada.
}

\begin{abstract}
Hyperkalemic periodic paralysis (HyperKPP) produces myotonia and attacks of muscle weakness triggered by rest after exercise or by $\mathrm{K}^{+}$ingestion. We introduced a missense substitution corresponding to a human familial HyperKPP mutation (Met1592 Val) into the mouse gene encoding the skeletal muscle voltage-gated $\mathrm{Na}^{+}$ channel $\mathrm{Na}_{v}$ 1.4. Mice heterozygous for this mutation exhibited prominent myotonia at rest and muscle fibertype switching to a more oxidative phenotype compared with controls. Isolated mutant extensor digitorum longus muscles were abnormally sensitive to the $\mathrm{Na}^{+} / \mathrm{K}^{+}$pump inhibitor ouabain and exhibited age-dependent changes, including delayed relaxation and altered generation of tetanic force. Moreover, rapid and sustained weakness of isolated mutant muscles was induced when the extracellular $\mathrm{K}^{+}$concentration was increased from $4 \mathrm{mM}$ to $10 \mathrm{mM}$, a level observed in the muscle interstitium of humans during exercise. Mutant muscle recovered from stimulation-induced fatigue more slowly than did control muscle, and the extent of recovery was decreased in the presence of high extracellular $\mathrm{K}^{+}$levels. These findings demonstrate that expression of the Met1592 $\mathrm{Val} \mathrm{Na}^{+}$channel in mouse muscle is sufficient to produce important features of HyperKPP, including myotonia, $\mathrm{K}^{+}$-sensitive paralysis, and susceptibility to delayed weakness during recovery from fatigue.
\end{abstract}

\section{Introduction}

Hyperkalemic periodic paralysis (HyperKPP) is one of several familial disorders of muscle excitability caused by missense mutations in the skeletal muscle $\mathrm{Na}^{+}$channel $\mathrm{Na}_{V} 1.4(1,2)$. $\mathrm{Na}_{\mathrm{V}} 1.4$ normally allows rapid propagation of the muscle action potential along the surface membrane and radially into the myofiber via the transverse $(\mathrm{t})$ tubules, where depolarization triggers $\mathrm{Ca}^{2+}$ release from the sarcoplasmic reticulum. Sarcolemmal excitability is transiently impaired during an attack of periodic paralysis (3). HyperKPP was originally distinguished from other forms of periodic paralysis by the absence of hypokalemia (4) and the observation of increasing serum $\mathrm{K}^{+}$levels during episodic attacks of limb muscle paralysis (5). Interictally, HyperKPP muscle may exhibit abnormal repetitive firing of muscle action potentials (myotonia) that produces muscle stiffness (6). Weakness can be provoked by immobility after strenuous exercise, ingestion of $\mathrm{K}^{+}$salts, fasting, cold exposure, emotional stress, or glucocorticoids (1, 7-10), although the triggers can be highly variable even among members of a single affected family. Attacks can be prevented by carbohydrate ingestion, mild exercise, thiazide diuretics, or carbonic anhydrase inhibitors $(1,11)$. The latter agents, and inhaled $\beta$-adrenergic agonists $(9,12)$ or intravenous calcium gluconate $(5,6)$, may also ameliorate symptoms during an attack. Despite treatment, however, individuals with HyperKPP fre-

Nonstandard abbreviations used: EDL, extensor digitorum longus; HyperKPP,

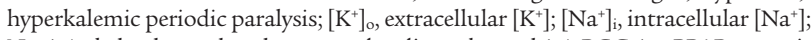
$\mathrm{Na}_{\mathrm{v}} 1.4$, skeletal muscle voltage-gated sodium channel 1.4; PGC-1 $\alpha$, PPAR $\gamma$ coactivator-1 $\alpha$; PGKneo, phosphoglycerate kinase-promoted neomycin phosphotransferase gene; $t$, transverse; $\mathrm{T}_{1 / 2 \mathrm{R}}$, time to half-relaxation.

Conflict of interest: The authors have declared that no conflict of interest exists. Citation for this article: J. Clin. Invest. 118:1437-1449 (2008). doi:10.1172/JCI32638. quently develop a slowly progressive vacuolar myopathy that affects proximal muscles by the third decade $(10,13,14)$.

The detection of an aberrantly increased inward $\mathrm{Na}^{+}$current in muscle from HyperKPP patients $(15,16)$ preceded the linkage of HyperKPP to a locus near the SCN4A gene encoding Nav1.4 (17). Subsequent studies identified more than 30 missense mutations in SCN4A among individuals with overlapping phenotypes of Hyper$\mathrm{KPP}$ and related disorders $(1,2,18)$. $\mathrm{Na}_{V} 1.4$ comprises a pore-forming $260-\mathrm{kDa}$ protein, the $\alpha$-subunit (Figure 1A), which associates with a $38-\mathrm{kDa} \beta_{1}$ subunit (19). The two most common mutations identified in HyperKPP include Thr704Met and Met1592Val, which have each been observed in approximately $30 \%$ of kindreds (10). Both of these substitutions are located in regions near the cytoplasmic face of the channel $\alpha$-subunit. Because distinct $\mathrm{Na}^{+}$ channel isoforms are present in skeletal muscle, cardiac muscle, brain, and peripheral nerve, mutations that alter the properties of $\mathrm{Na}_{V} 1.4 \alpha$-subunits are not expected to affect $\mathrm{Na}^{+}$channel function in tissues other than skeletal muscle.

Electrophysiological studies of mutant $\mathrm{Na}^{+}$channels in heterologous expression systems have demonstrated functional abnormalities that may contribute to the phenotypic heterogeneity observed among different families with HyperKPP and related myotonic disorders $(1,2)$. For instance, HyperKPP mutant $\mathrm{Na}^{+}$channels can exhibit enhanced activation, impaired slow inactivation, and a persistent noninactivating inward current (20-22). In contrast, other $\mathrm{Na}^{+}$channel mutants that cause myotonic phenotypes without weakness typically show impaired fast inactivation but do not maintain a persistent $\mathrm{Na}^{+}$current (2). A 2-compartment model of the muscle surface membrane and tubule system suggested that the exaggerated excitability in HyperKPP depends on both 
A
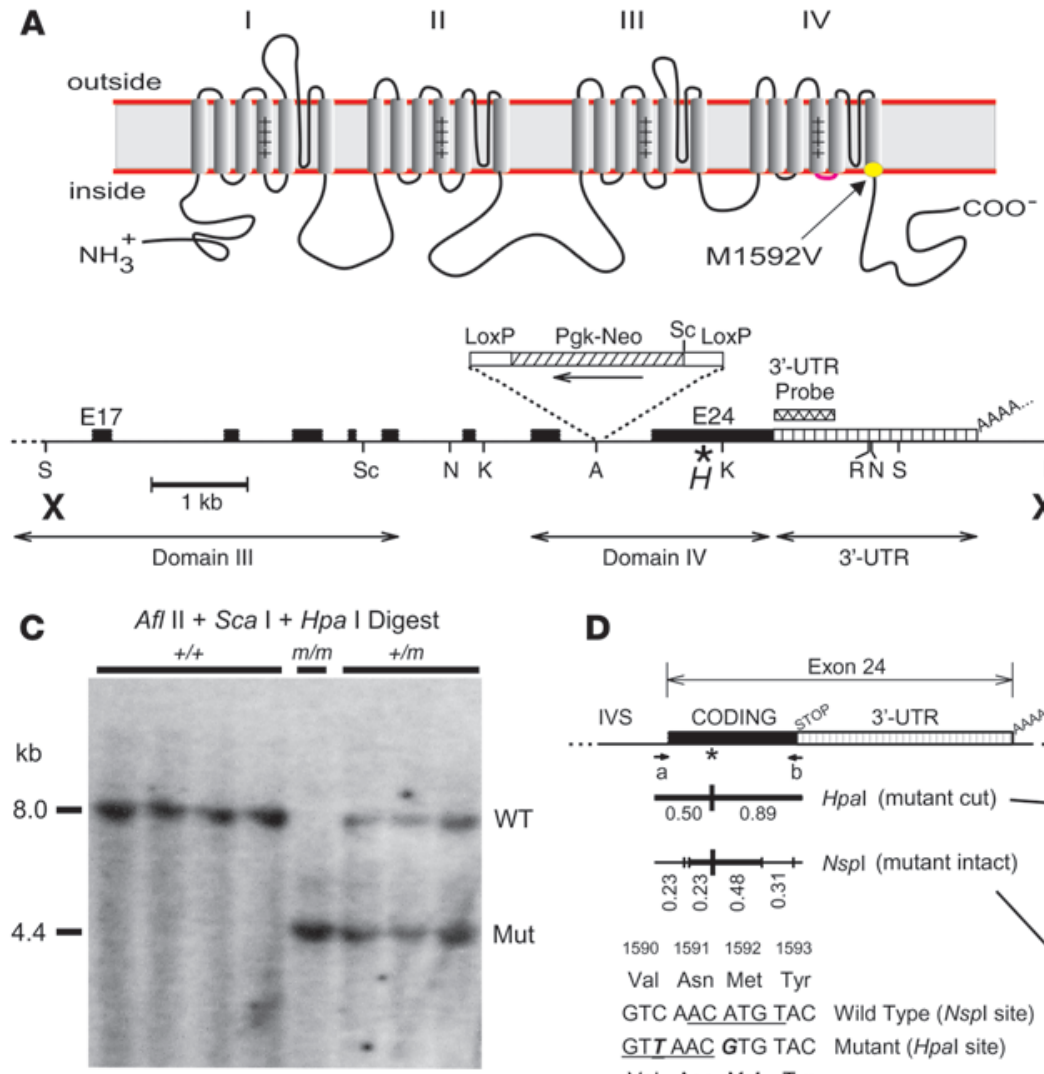

External Probe Pgk-Neo Sc LoxP

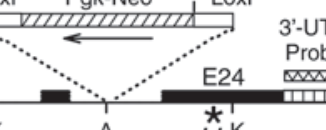

A $\quad \stackrel{*}{H}^{\mathrm{K}}$

Domain IV
D

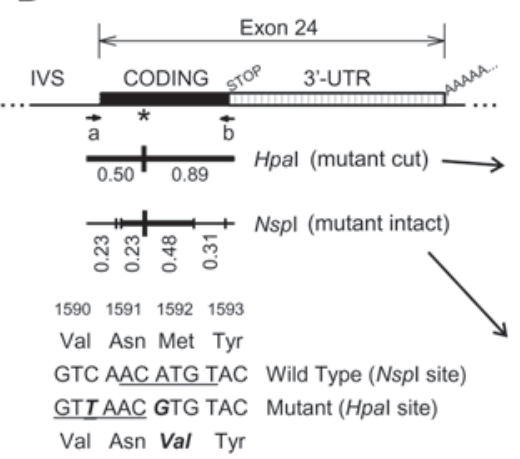

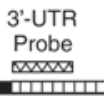

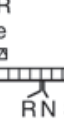
RN S

$\mathbf{X}$

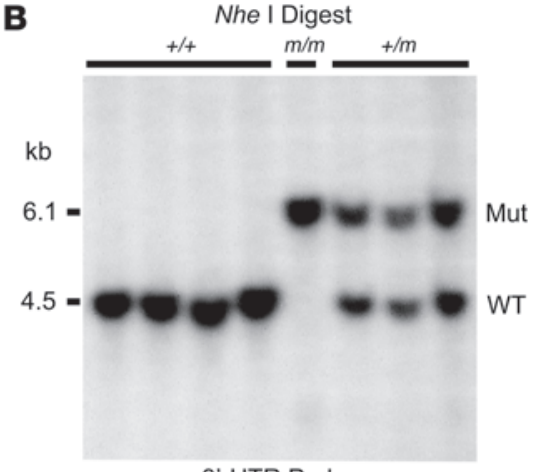

3'-UTR Probe

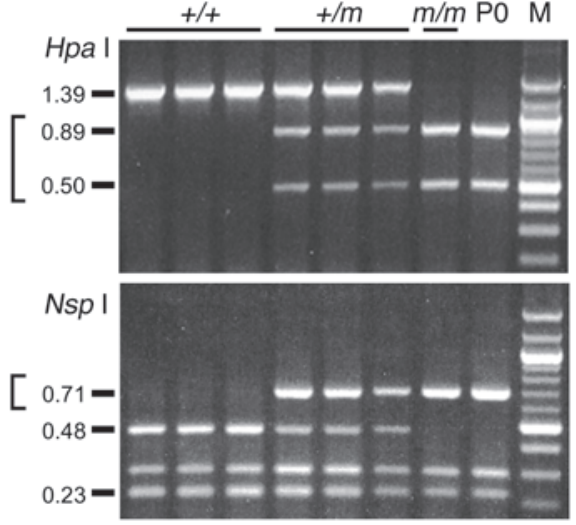

Figure 1

Knock-in of human Met1592Val variant into mouse Nav1.4 gene. (A) Na+ channel topology and the location of the Met1592Val substitution within the S6 segment of domain IV (top). The mNav1.4 targeting sequence (bottom) encompassed exons 17-24 (black boxes) and the $3^{\prime}-$ UTR of exon 24 (hatched area), while the PGKneo selection gene was inserted within intron 23. The Met $\rightarrow$ Val mutation $\left(^{*}\right)$ and the silent $H p a l$ site $(\mathrm{H})$ are indicated within exon 24. Bold X's indicate the limits of the targeting sequence. Shown are the internal and external hybridization probe regions and restriction enzyme sites for Avrll (A), AfllI (A2), Kpnl (K), Nhel (N), EcoRI (R), Sacl (S), and Scal (Sc). (B) Southern blot of Nhel-digested mouse genomic DNA (10 $\mu \mathrm{g}$ per lane) hybridized with the internal $3^{\prime}$-UTR probe demonstrates a $4.5-\mathrm{kb}$ wild-type allele or a 6.1 -kb allele produced by insertion of the PGKneo gene. Genotype is indicated for wild-type $(+/+)$, heterozygous mutant $(+/ \mathrm{m})$, and homozygous mutant $(\mathrm{m} / \mathrm{m})$ alleles. (C) Southern blot of DNA digested with Aflll plus Hpal plus Scal and hybridized to the external probe identifies an 8.0-kb wild-type allele (Scal-AfIII fragment) and a $4.4 \mathrm{~kb}$ mutant allele (Hpal-Aflll fragment). (D) Genotyping by analysis of a 1.39-kb PCR product amplified from exon 24 using primers a and b (see Supplemental Methods). The mutant allele contained a novel Hpal site and lacked one of the 5 Nspl sites present in the wild-type allele (indicated by thick vertical lines under the asterisk, with sequence shown below). The lane labeled "M" shows a 100-bp marker DNA ladder.

the proportion of noninactivating $\mathrm{Na}^{+}$channels and the degree of activity-driven $\mathrm{K}^{+}$accumulation within $\mathrm{t}$ tubules $(21,23,24)$. Consistent with this, electrophysiological analyses of muscle bundles from individuals with HyperKPP show that paralysis is caused by aberrant depolarization of the muscle membrane $(3,15,16,25)$, but a link to the clinical triggers is incompletely understood.

The aim of the present study was to determine whether introduction of a mutation corresponding to the human Met1592Val substitution into the mouse $\mathrm{Na}_{V} 1.4$ gene produces features similar to HyperKPP in mice and provides new insights regarding the disease mechanisms. While all individuals with HyperKPP share a $\mathrm{K}^{+}$-sensitive phenotype $(1,26)$, considerable variability exists with respect to the triggers and severity of attacks in vivo $(10,14)$. Furthermore, inducible attacks of human HyperKPP occur with quite unpredictable success, and the relationship of factors such as muscle cooling to symptoms is not well defined. For example, exercise and cold are reported as triggers of weakness by patients with the Met 1592Val mutation, but only with probabilities of 0.73 and 0.38 , respectively (10). While improved electrodiagnostic tests show promise in discriminating among different subgroups of muscle channelopathies $(27,28)$, an in vitro muscle preparation could allow further dissection of the complex physiological interactions that contribute to episodic paralysis. Given the clinical variability among individuals with HyperKPP, the first objective was therefore to determine whether the mutant mice exhibit 4 physiological hallmarks of the disease, including (a) myotonic activity in vivo; (b) reduced muscle force development at elevated extracellular $\left[\mathrm{K}^{+}\right]\left(\left[\mathrm{K}^{+}\right]_{\mathrm{o}}\right)$ in vitro mimicking episodic paralysis; (c) amelioration of weakness with increased $\left[\mathrm{Ca}^{2+}\right]_{\mathrm{o}}$ in vitro; and (d) development of nonepisodic muscle weakness with aging. 
A

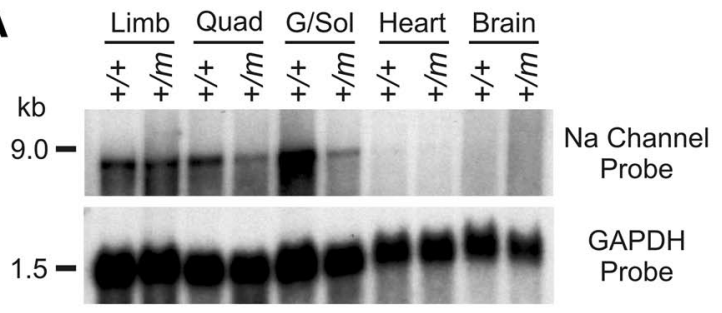

B
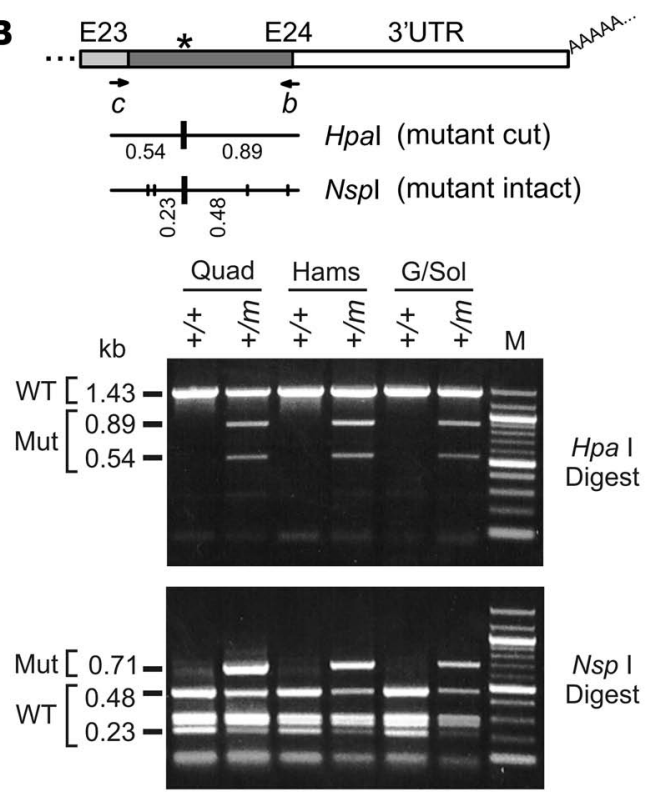

C

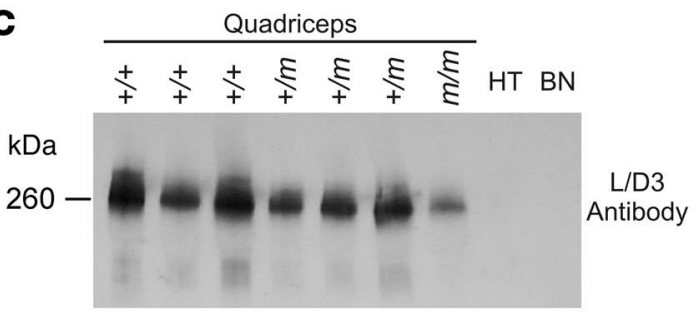

In response to changes in functional demands, skeletal muscle fibers can modulate their metabolic capacity, contractile protein expression, and susceptibility to fatigue (29-31). Increased muscle activity produces adaptive changes via calcineurin-dependent signaling (32) and transcriptional regulators such as PPAR $\gamma$ coactivator-1 $\alpha$ (PGC-1 $\alpha$ ) (33). PGC-1 $\alpha$ not only increases expression of slow-twitch muscle contractile protein isoforms by coactivating myocyte enhancer factor 2 (Mef2) transcription factors but also induces mitochondrial biogenesis and increases oxidative metabolism by coactivating nuclear respiratory factor 1 (Nrf1) (33). The second objective was therefore to examine whether chronically altered muscle activity resulting from mutant $\mathrm{Na}^{+}$ channel expression (e.g., myotonia) alters the muscle fiber composition, oxidative capacity, or expression of PGC-1 $\alpha$. Furthermore, because vacuolar myopathy often develops over time in HyperKPP despite effective management of paralytic attacks, a better understanding of the causative mechanism is needed. The third objective was to determine whether more chronic pathological changes observed in HyperKPP also occur in the mouse model with aging.

\section{Figure 2}

Mutant $\mathrm{Na}^{+}$channel mRNA and protein are expressed in mouse skeletal muscle tissue. (A) Northern blots of total RNA extracted from pooled hind-limb skeletal muscle, quadriceps, gastrocnemius/soleus, heart, or brain tissues ( $5 \mu \mathrm{g}$ loaded per lane; $n=3-8$ mice per group). The $3^{\prime}$-UTR probe specific for mNav1.4 hybridized to an 8.5 -kb full-length $\mathrm{Na}^{+}$channel mRNA in both normal $(+/+)$and mutant $(+/ m)$ muscle samples but not those from heart or brain (top panel). The blot was rehybridized with a GAPDH probe (bottom panel). (B) RT-PCR of total RNA from $(+/+)$ or $(+/ m)$ mouse muscle using primers $c$ (exon 23$)$ and $b$ (exon 24). Digestion of the mutant RT-PCR product with Hpal (producing $0.89-\mathrm{kb}$ and $0.54-\mathrm{kb}$ fragments) or $\mathrm{Nspl}$ (preserving a $0.71-\mathrm{kb}$ fragment) demonstrated that approximately $30 \%-50 \%$ of transcripts in mutant muscle encoded the Met1592Val variant. The lane labeled "M" shows a 100-bp marker DNA ladder. (C) Western blot of membrane proteins isolated from $(+/+),(+/ \mathrm{m})$, or $(\mathrm{m} / \mathrm{m})$ mouse quadriceps muscle, heart $(\mathrm{HT})$, and brain (BN) tissues (10 $\mu \mathrm{g}$ loaded per lane). The L/D3 monoclonal antibody specifically recognizes $\mathrm{Na}_{v} 1.4$ but not cardiac or brain $\mathrm{Na}^{+}$channel isoforms.

\section{Results}

Targeted substitution of HyperKPP variant Met1592Val into mouse $\mathrm{Na}$ 1.4. We introduced a mutation corresponding to human Met1592Val (Figure 1A) into the gene encoding mouse $\mathrm{Na}_{V} 1.4\left(\mathrm{mNa}_{V} 1.4\right)$ by homologous recombination to produce the line B6.129S4Scn $4 a^{\text {tm1Ljb }}$ (see Supplemental Methods; supplemental material available online with this article; doi:10.1172/JCI32638DS1). A 630-bp unique 3'-UTR probe identified 3 BAC clones derived from a mouse $129 / \mathrm{Sv}$ ES cell library that contained $\mathrm{mNa}_{V} 1.4$ genomic sequence. Restriction mapping and sequence analysis of the region encompassing exons 17-24 revealed exon/intron boundaries identical to that of the human $\mathrm{Na}_{\mathrm{V}} 1.4$ gene (34).

A 12.1-kb targeting sequence for homologous recombination introduced the disease mutation and an adjacent silent HpaI site into exon 24 (Figure 1A). The phosphoglycerate kinase-promoted neomycin phosphotransferase gene (PGKneo) was inserted in reverse orientation to that of $\mathrm{Na}_{v} 1.4$ to minimize interference with transcription of the $\mathrm{Na}^{+}$channel gene. G418-resistant mouse ES cells that acquired the loxP-PGKneo-loxP insertion and the unique HpaI marker were used to produce chimeric founder mice. Germline integration of loxP-PGKneo-loxP was confirmed by Southern blot analysis (Figure 1B), and localization of the mutant HpaI site to the correct genetic locus was confirmed by hybridization of an external probe (Figure 1C).

The presence of both the silent HpaI marker and the actual HyperKPP mutation (causing loss of an NspI site) were verified during breeding using PCR amplification of genomic DNA followed by restriction digestion (Figure $1 \mathrm{D}$ ). When heterozygous mutant $(+/ m)$ mice were bred with each other, we observed the following genotype frequencies at 30 days of age ( $n=146$ offspring): normal $(+/+), 35.6 \%(n=52)$; heterozygous mutant $(+/ m), 63.0 \%(n=92)$; and homozygous mutant $(\mathrm{m} / \mathrm{m}), 1.4 \%(n=2)$. These results indicated that (a) the $(\mathrm{m} / \mathrm{m})$ genotype was underrepresented at 30 days $\left(P<0.001\right.$ using $\chi^{2}$ analysis $)$, and (b) there was no selection bias against the heterozygous $(+/ m)$ genotype by 30 days $(P=0.54$ for selection). Occasionally, we also observed dead pups within a day after birth; we genotyped one such litter and found that all 4 dead pups exhibited the $(\mathrm{m} / \mathrm{m})$ genotype (Figure $1 \mathrm{D}$; lane $\mathrm{P} 0$ is representative), suggesting that selection against $(\mathrm{m} / \mathrm{m})$ may occur by the first postnatal day $(P<0.05)$. Overall, these observations imply that the absence of a normal $\mathrm{mNa}_{\mathrm{V}} 1.4$ allele in $(\mathrm{m} / \mathrm{m})$ homozygous mutants 


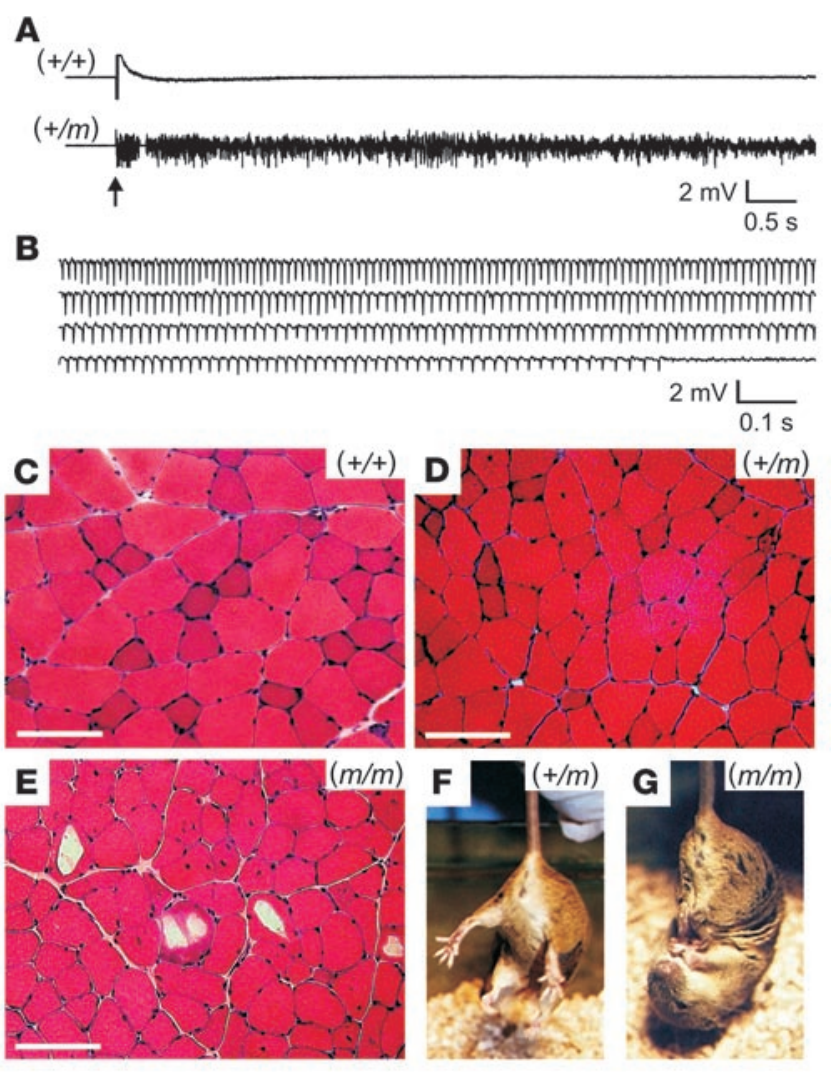

greatly impairs either embryonic or early postnatal survival, while the heterozygous state does not significantly affect early viability.

Mutant $\mathrm{Na}^{+}$channel $m R N A$ and protein expression in skeletal muscle. Total RNA was isolated from hind-limb muscles, heart, and brain from $(+/+)$ or $(+/ m)$ mice, and Northern blot analysis using a hybridization probe specific for $\mathrm{Na}_{V} 1.4$ transcripts identified an 8.5-kb mRNA in skeletal muscle that was absent from heart and brain tissues (Figure 2A). Digestion of an RT-PCR product with HpaI or NspI identified expression of mutant $\mathrm{Na}_{\mathrm{V}} 1.4$ mRNA in all $(+/ m)$ muscles examined (Figure $2 \mathrm{~B})$. The Met $1592 \mathrm{Val}$ mutant sequence constituted $42 \% \pm 11 \%$ of the total Nav1.4 RT-PCR products from each heterozygous muscle as quantified by optical density of the digested PCR product.

The expression of $\mathrm{mNa}_{V} 1.4$ protein was determined by Western blot analysis using the L/D3 antibody, which specifically recognizes the skeletal muscle $\mathrm{Na}^{+}$channel isoform (19). A 260-kDa species, consistent with $\mathrm{mNa}_{V} 1.4$, was observed in each quadriceps sample but not in membrane proteins from heart or brain (Figure $2 \mathrm{C}$ ). Total $\mathrm{mNa}_{\mathrm{V}} 1.4$ protein expression as determined by Western blot appeared slightly decreased, by $1.4 \pm 0.4$-fold, in mutant $(+/ \mathrm{m})$ compared with normal $(+/+)$ muscle membranes, but this difference did not reach statistical significance $(P=0.07)$. Although $\mathrm{mNa}_{\mathrm{V}} 1.4$ appeared decreased by approximately 3 -fold in $(\mathrm{m} / \mathrm{m})$ compared with normal $(+/+)$ muscle, perhaps reflecting downregulation of poorly inactivating $\mathrm{Na}^{+}$channels in the absence of the normal allele, the small sample size for $(\mathrm{m} / \mathrm{m})$ did not allow statistical validation of this difference.

Myotonia in $(+/ m)$ mutant muscle and accelerated myopathic abnormalities in $(\mathrm{m} / \mathrm{m})$ muscle. Heterozygous $(+/ \mathrm{m})$ mice had normal locomotor activity without any observed spontaneous episodes of

\section{Figure 3}

Heterozygous mutant $(+/ m)$ muscle from young mice exhibited myotonia and only subtle myopathy, while homozygous $(\mathrm{m} / \mathrm{m})$ mutant muscle exhibited abnormal limb clasping and prominent myopathic changes. (A) Electromyography of hind-limb muscle from normal (+/+) anesthetized mice showed electrical silence except upon insertion (arrow) or movement of the recording electrode. Electromyograms from mutant $(+/ m)$ mice under the same conditions, without exception, exhibited high background activity and audible characteristics consistent with widespread myotonia ( $n>60$ for both groups). (B) Runs of myotonia (sustained repetitive firing with varying amplitude and frequency) occurred spontaneously or could be easily elicited upon needle movement for $(+/ m)$ muscle (shown) but not for normal muscle (see Supplemental Videos 1 and 2). (C-E) H\&E staining of hamstring muscle from a $(+/+)$ mouse at 4 months of age exhibited a normal pattern of fiber size variation and peripheral nuclei $(\mathbf{C})$, while that from a $(+/ \mathrm{m})$ mouse at 4 months showed mildly increased internalized nuclei (D). The same muscle from a $(\mathrm{m} / \mathrm{m})$ mouse at 2.8 months exhibited increased fiber size variation, frequent internalized nuclei, and large scattered vacuoles at various stages of evolution (E). Scale bars in C-E: $100 \mu \mathrm{m}$. (F) Normal extension of hind limbs observed for a $(+/ \mathrm{m})$ mouse at 2.8 months of age upon being held by the tail. (G) Abnormal clasping response exhibited by a $(\mathrm{m} / \mathrm{m})$ sibling at 2.8 months. This $(\mathrm{m} / \mathrm{m})$ mouse also had prominent hind-limb weakness and decreased locomotor activity compared with its $(+/ m)$ sibling (see Supplemental Video 4).

weakness. However $(+/ m)$ mice exhibited increased muscle irritability during electromyography in response to needle movement and robust myotonia in hind-limb muscles from at least 1 month of age, while control $(+/+)$ siblings had normal excitability and no electrical myotonia (Figure 3, A and B, and Supplemental Videos 1 and $2 ; n>60$ for each group). Histological examination of muscle from $(+/ m)$ mice at 4 months of age suggested only mild myopathic changes compared with that from normal siblings (Figure 3, C and $\mathrm{D}$ ), with scattered internalized nuclei suggesting regeneration of damaged muscle fibers by satellite cells. Compared with their $(+/ m)$ siblings, the 2 surviving homozygous $(\mathrm{m} / \mathrm{m})$ mice showed (a) obvious fixed limb weakness with muscle atrophy and (b) unusual hind-limb clasping behavior when lifted by the tail (examples shown in Figure 3G and Supplemental Video 3). At 2.8 months of age $(\mathrm{m} / \mathrm{m})$ muscle revealed prominently increased fiber size variation, frequent internalized nuclei, and large vacuolar structures within muscle fibers that contained a pale amorphous material (Figure $3 \mathrm{E})$. This female $(\mathrm{m} / \mathrm{m})$ mouse weighed only $16.6 \mathrm{~g}$ at 2.8 months, compared with $20.9 \pm 1.2 \mathrm{~g}(n=6)$ for $(+/ m)$ and $21.4 \pm 1.3 \mathrm{~g}$ $(n=5)$ for normal $(+/+)$ age-matched female mice.

Age-related progression of myopathy in mutant mice and muscle fiber type switching toward a more oxidative phenotype. The myopathic abnormalities observed at 4 months of age increased with aging, such that 2-year-old $(+/ \mathrm{m})$ mice exhibited more prominent fiber size variation and internalized nuclei compared with controls (Figure 4, A and B). Staining of tibialis anterior muscle for succinate dehydrogenase $(\mathrm{SDH})$ activity revealed a change from a mixture of glycolytic and oxidative fibers in normal $(+/+)$ muscle (Figure $4 \mathrm{C}$ ) to a more oxidative pattern in $(+/ m)$ muscle (Figure $4 \mathrm{D})$, which was also confirmed by NADH staining (data not shown). Furthermore, 


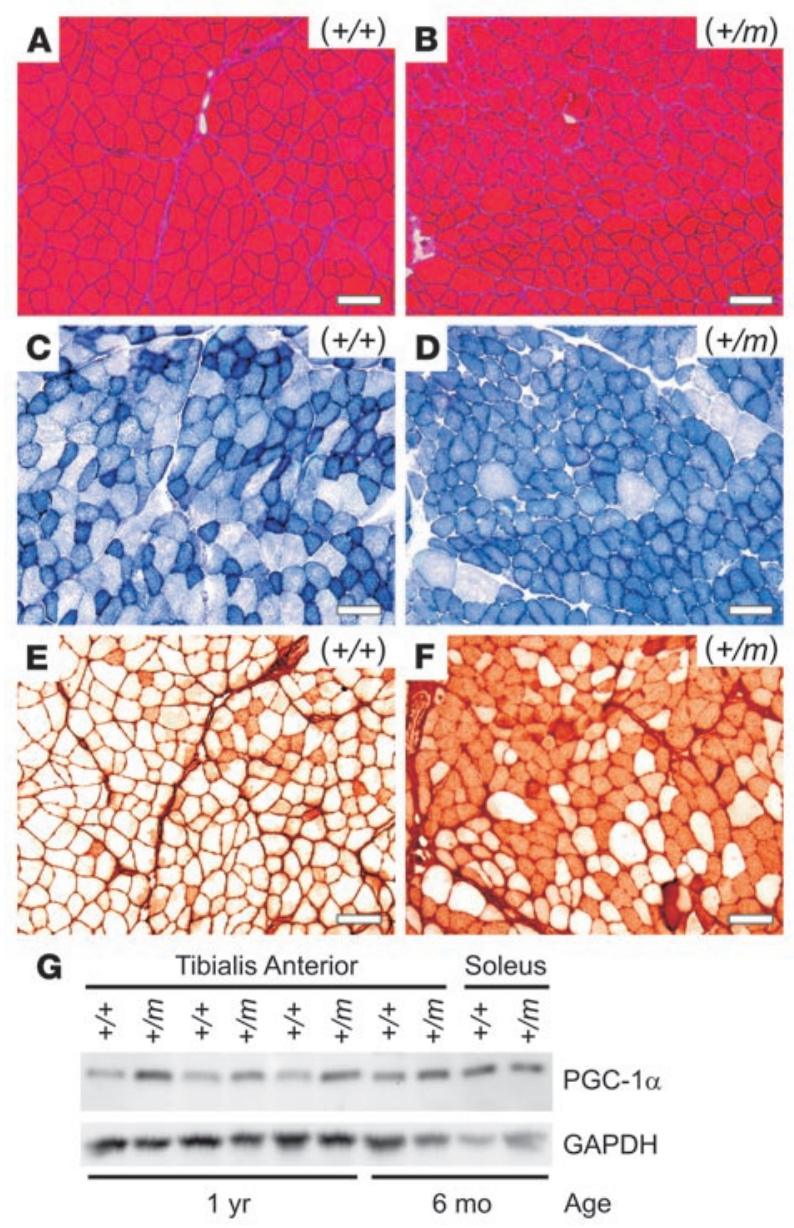

myosin immunostaining (35) revealed a large increase in type IIA fibers in the mutant tibialis anterior muscle compared with control (Figure 4, E and F). A similar shift toward a more oxidative muscle phenotype was observed for quadriceps and gastrocnemius muscles in $(+/ m)$ compared with $(+/+)$ muscles (data not shown).

The contents of PGC- $1 \alpha$ and the glycolytic enzyme GAPDH in muscle lysates were detected by Western blotting, with equal amounts of total protein loaded per lane (Figure 4G). We observed an increase of PGC- $1 \alpha$ by $2.1 \pm 0.5$-fold $(P<0.05)$ in mutant compared with normal tibialis anterior muscle at 1 year of age. This increased level did not differ significantly from the normal level of PGC-1 $\alpha$ in soleus $(P=0.53)$, a slow-twitch oxidative muscle. The higher glycolytic capacity of normal tibialis anterior compared with soleus muscle was reflected by a $2.4 \pm 0.6$-fold higher GAPDH content $(P<0.01)$ on the same blot. We observed that mutant tibialis anterior muscle at 1 year of age expressed only slightly lower GAPDH compared with control ( $86 \% \pm 8 \%$ of control, $P=0.05)$, suggesting that the mutant muscle retained a high glycolytic capacity. The signal ratio of PGC- $1 \alpha$ to GAPDH should be independent of loading variation and provides a relative oxidative index, with largest values expected for slow oxidative muscle (type I), intermediate values for fast oxidative-glycolytic muscle (type IIA), and lowest values for fast glycolytic muscle (type IIB). This ratio increased by $2.4 \pm 0.5$-fold for mutant compared with control tibialis anterior muscles $(P<0.05)$. The maintenance of a high GAPDH level and the increase in PGC-1 $\alpha$ are consistent with our independent observa-

\section{Figure 4}

Mutant $(+/ m)$ muscles from older mice exhibited mild myopathic changes, a more oxidative fiber type, and upregulation of the transcriptional coactivator PGC-1 $\alpha$. (A and B) H\&E staining of tibialis anterior muscle from a normal $(+/+)$ mouse at 24 months of age exhibited a normal pattern of fiber size variation and peripheral nuclei $(\mathbf{A})$, while that from a mutant $(+/ m)$ sibling mouse showed increased fiber size variation and more frequent internalized nuclei (B). (C and D) Succinate dehydrogenase (SDH) staining of serial sections revealed a mixed pattern of oxidative (dark) and glycolytic (light) fibers for tibialis anterior muscle from the normal $(+/+)$ mouse $(\mathbf{C})$, while that from the $(+/ m)$ mouse showed an increase of SDH-positive fibers, indicating a more oxidative phenotype (D). ( $E$ and F) Immunostaining of serial sections with A4.74 myosin antibody confirmed a large increase in fast oxidative fibers (type IIA) in the mutant $(+/ \mathrm{m})$ compared with the normal $(+/+)$ muscle. Scale bars in A-F: $100 \mu \mathrm{m}$. (G) Western blot (2 $\mu \mathrm{g}$ of soluble muscle lysate protein per lane as determined by BCA assay) showed increased expression of PGC- $1 \alpha$ by $2.1 \pm 0.5$-fold in tibialis anterior muscle from 1-year-old $(+/ m)$ mice compared with controls.

tions of a shift toward type IIA immunostaining (Figure 4, E and F) and a more fatigue-resistant phenotype (see below) for mutant muscles that contain fast fibers. Furthermore, these results suggest that PGC- $1 \alpha$ may be involved in specifying properties of type IIA in addition to type I myofibers (33).

Reduced contractile force and slowed relaxation in mutant $(+/ m)$ muscle. To evaluate muscle contractile properties under defined physiological conditions, we isolated extensor digitorum longus (EDL) muscle from 8- to 14-month-old mice and recorded the twitch force produced by direct stimulation with 1-ms current pulses in an organ bath at $25^{\circ} \mathrm{C}$ (Figure $5 \mathrm{~A}$ ). Under baseline ionic conditions of $4 \mathrm{mM}\left[\mathrm{K}^{+}\right]_{\mathrm{o}}$ and $2 \mathrm{mM}\left[\mathrm{Ca}^{2+}\right]_{\mathrm{o}}$, a single supramaximal current pulse elicited twitch force from mutant EDL muscle that was only $44 \%$ of that generated by age-matched control muscle (Figure 5A, $P<0.01)$. Furthermore, although the rapidity of contraction was similar for both groups, the time to half-relaxation (twitch $T_{1 / 2 R}$ ) was increased by $69 \%$ for mutant compared with control muscles $(P<0.01)$. Measurements from a group of younger mice (ages 3-5 months) showed a lesser degree of abnormality, with peak twitch force reduced to $72 \%$ of control $(P=0.04)$ and twitch $\mathrm{T}_{1 / 2 \mathrm{R}}$ increased by only $27 \%(P=0.11$, not significant $)$ for mutant $(n=6)$ compared with control $(n=10)$ EDL muscle (data not shown).

We next evaluated contractile properties in response to tetanic stimulation using 1-ms current pulses applied at 20,50, or 100 $\mathrm{Hz}$ (Figure 5B). For mutant $(+/ m)$ compared with normal $(+/+)$ EDL from older mice, the kinetics of force buildup (tetanic rise $\tau$ ) during $50-$ and $100-\mathrm{Hz}$ stimulation were prolonged by $110 \%$ $(P<0.01)$ and 54\% $(P<0.01)$, respectively (Figure 5B). Muscle relaxation from the last stimulus applied during a $50-$ or $100-\mathrm{Hz}$ pulse train (tetanic $\mathrm{T}_{1 / 2 \mathrm{R}}$ ) was also prolonged, by $39 \%(P<0.01)$ and $30 \%$ $(P<0.01)$, respectively, for mutant compared with control EDL muscle. The delayed relaxation likely contributed to the greater degree of force buildup (peak tetanic force/single-twitch force ratio) observed for mutant compared with control muscle during 50- and $100-\mathrm{Hz}$ stimulation (Figure 5B, $P<0.01$ ). Mutant EDL also had $34 \%$ less tetanic force $(P<0.05)$ elicited during $100-\mathrm{Hz}$ stimulation when compared with control EDL muscle. The group of younger mice (ages 3-5 months) showed prolongation of the tetanic rising phase $\tau$ by only $39 \%(P=0.01)$ and $30 \%(P=0.04)$ and the tetanic $\mathrm{T}_{1 / 2 \mathrm{R}}$ by only $26 \%(P<0.01)$ and $22 \%(P<0.01)$ during 50 - and $100-\mathrm{Hz}$ stimulation, respectively (data not shown). Over- 
A
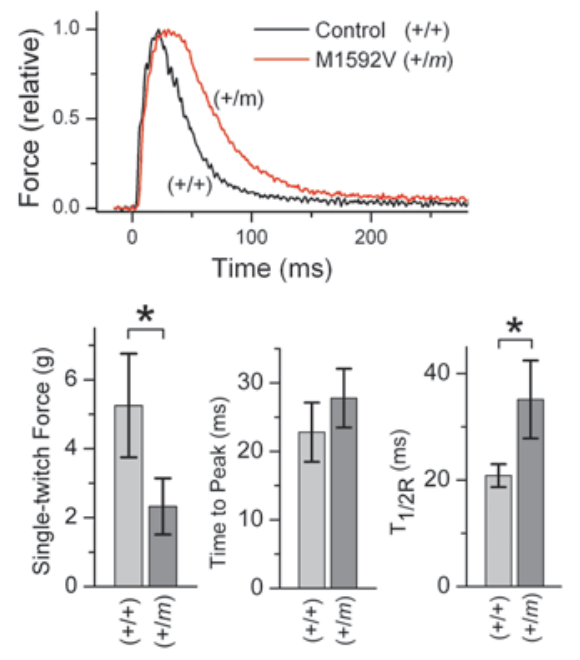

B
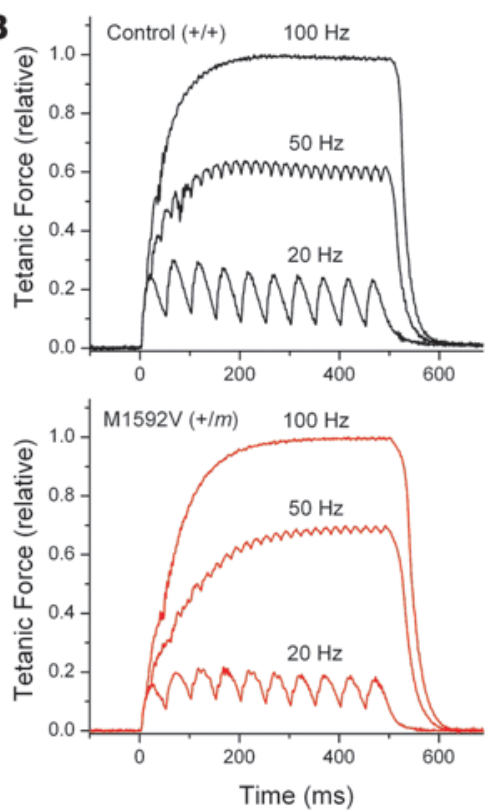
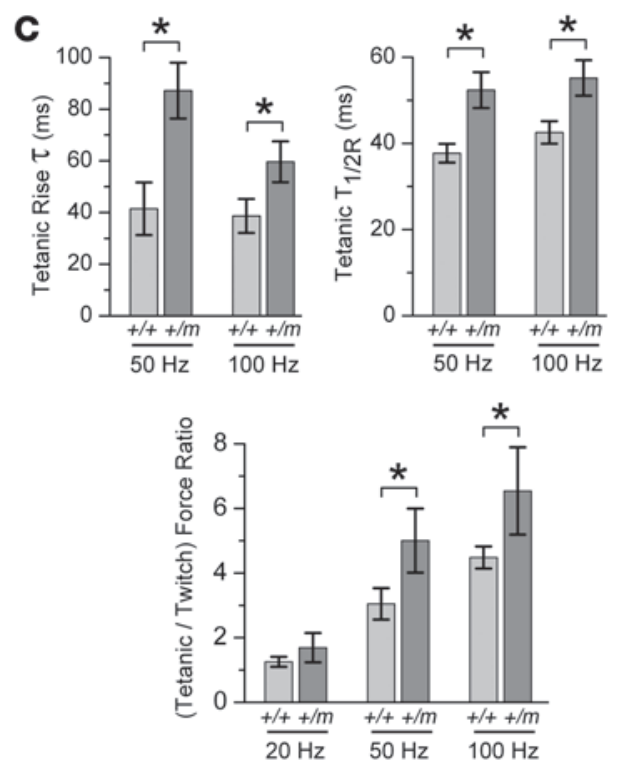

Figure 5

Reduced force and slowed relaxation of mutant $(+/ m)$ compared with normal $(+/+)$ EDL muscle contributed to altered contractile properties. (A) Single-twitch contraction produced by a $1-\mathrm{ms}$ supramaximal current pulse to isolated EDL muscle from a mutant $(+/ \mathrm{m})$ or a normal $(+/+)$ mouse. Responses were normalized to the peak force for comparison of kinetics. Bar graphs (mean \pm SD) indicate decreased peak force by 2.3 -fold, no change for time to peak, and increased $\mathrm{T}_{1 / 2 \mathrm{R}}$ by 1.7 -fold for mutant $(n=9,10.6 \pm 2.2$ months old) compared with normal ( $n=5,11.4 \pm 1.8$ months old) EDL muscles. (B) Tetanic contraction produced by 1 -ms pulse trains lasting 0.5 seconds at 20,50, or $100 \mathrm{~Hz}$ for the same EDL muscles as in A. Records are normalized to the peak force during $100-\mathrm{Hz}$ stimulation. The kinetics of force buildup (tetanic rise $\tau$ ) and the tetanic $\mathrm{T}_{1 / 2 \mathrm{R}}$ from the last stimulus were both prolonged for mutant compared with normal EDL during 50- and $100-\mathrm{Hz}$ stimulation. The ratio of maximal tetanic force to single-twitch force was significantly increased for mutant compared with control muscle at $50-$ and $100-\mathrm{Hz}$ stimulation. Bar graphs show mean \pm SD. ${ }^{*} P<0.01,2$-tailed Student's $t$ test.

all, these results indicated that expression of mutant $\mathrm{Na}_{\mathrm{V}} 1.4$ channels in EDL muscle can alter the magnitude and rate of tetanic force generation in an age-dependent manner.

Sustained weakness of mutant EDL muscle upon exposure to $10 \mathrm{mM}$ $\left[\mathrm{K}^{+}\right]_{0}$. We next examined the consequences of altered extracellular $\mathrm{K}^{+}$and $\mathrm{Ca}^{2+}$ upon peak contractile force for normal $(+/+)$ and mutant $(+/ m)$ muscle. As shown in Figure 6 , isolated EDL muscles were equilibrated in a starting bath solution containing $4 \mathrm{mM}$ $\left[\mathrm{K}^{+}\right]_{\mathrm{o}}$ and $1.3 \mathrm{mM}\left[\mathrm{Ca}^{2+}\right]_{\mathrm{o}}$, and the peak tetanic force obtained every 3 minutes was normalized to the force produced at the start of the stimulation protocol. We initially tested whether EDL muscles expressing the mutant $\mathrm{Na}^{+}$channel showed any unexpected sensitivity to low $\left[\mathrm{K}^{+}\right]_{\mathrm{o}}$ (Figure $6 \mathrm{~A}$ ). Upon reduction of $\left[\mathrm{K}^{+}\right]_{\mathrm{o}}$ from $4 \mathrm{mM}$ to $1.2 \mathrm{mM}$, the mutant muscle exhibited a mild decrease in tetanic force that did not differ from control $(P=0.15)$. The test condition was followed by exposure to a recovery solution containing normal $\left[\mathrm{K}^{+}\right]_{\mathrm{o}}(4 \mathrm{mM})$ and elevated $\left[\mathrm{Ca}^{2+}\right]_{\mathrm{o}}(4 \mathrm{mM})$ to assess for reversibility of any observed changes. The rationale for the elevated $\left[\mathrm{Ca}^{2+}\right]_{\mathrm{o}}$ is that $\mathrm{Ca}^{2+}$ can help to repolarize the muscle cell membrane $(36,37)$ should any of the test conditions cause depolarization-induced weakness. As shown in Figure 6A, the mutant muscle regained force more rapidly than control in the recovery solution $(P<0.01)$. For the experiments in Figure 6, A-D, and Figure 7, B and C, the recovery from each test occurred in $4 \mathrm{mM}\left[\mathrm{K}^{+}\right]_{\mathrm{o}}$ and $4 \mathrm{mM}\left[\mathrm{Ca}^{2+}\right]_{\mathrm{o}}$.

We next evaluated the effects of mildly raising $\left[\mathrm{K}^{+}\right]_{\mathrm{o}}$ from $4 \mathrm{mM}$ to $8 \mathrm{mM}$ upon EDL contraction. As shown in Figure 6B, upon raising external $\left[\mathrm{K}^{+}\right]_{\mathrm{o}}$, the peak tetanic force for mutant EDL transiently decreased by $46 \%$ within 5 minutes $(P<0.001)$, while con- trol EDL increased by 3\%. The mutant EDL recovered back to the baseline force within 15 minutes despite continued exposure to $8 \mathrm{mM}\left[\mathrm{K}^{+}\right]_{\mathrm{o}}$, indicating that this level of $\left[\mathrm{K}^{+}\right]_{\mathrm{o}}$ was insufficient to produce sustained weakness. During moderate exercise in humans, the muscle interstitial $\left[\mathrm{K}^{+}\right]$normally reaches $8-10 \mathrm{mM}$, being 4-6 $\mathrm{mM}$ higher than venous $\left[\mathrm{K}^{+}\right](38)$. So, although individuals with HyperKPP typically experience severe weakness associated with venous $\left[\mathrm{K}^{+}\right]$levels acutely rising to only $4.5-6.5 \mathrm{mM}$, the increase is expected to be greater in the muscle interstitium and most likely within the tubules.

We thus hypothesized that $10 \mathrm{mM}\left[\mathrm{K}^{+}\right]_{\mathrm{o}}$ would more closely mimic the interstitial $\left[\mathrm{K}^{+}\right]$level achieved during an attack of HyperKPP triggered after exercise. Figure $6 \mathrm{C}$ shows that within 7 minutes after raising $\left[\mathrm{K}^{+}\right]_{\text {o }}$ to $10 \mathrm{mM}$, we observed a dramatic loss of force by $88 \%$ for mutant compared with only $9 \%$ for control $(P<0.001)$, and the mutant partially recovered within 15 minutes. Furthermore, while exposure of EDL to $10 \mathrm{mM}\left[\mathrm{K}^{+}\right]_{\mathrm{o}}$ for $28 \mathrm{~min}$ utes caused a mild monophasic decline in force by $22 \%$ for control, the mutant muscle exhibited an additional late phase of force decline to less than $30 \%$ of the starting value $(P<0.001)$. The weakness was reversible, since the mutant muscle quickly regained full force upon exposure to the recovery solution.

Prolonged muscle activity can result in a depletion of t-tubular $\mathrm{Ca}^{2+}(39)$, so the myotonic activity of mutant muscle may also be expected to lower the t-tubular $\left[\mathrm{Ca}^{2+}\right]$. Furthermore, in contrast to elevated $\left[\mathrm{Ca}^{2+}\right]_{0}$, lowered $\left[\mathrm{Ca}^{2+}\right]_{0}$ can worsen tetanic weakness of normal mouse EDL muscle subjected to impaired $\mathrm{K}^{+}$and $\mathrm{Na}^{+}$ gradients by contributing to action potential failure (37). Indeed, 


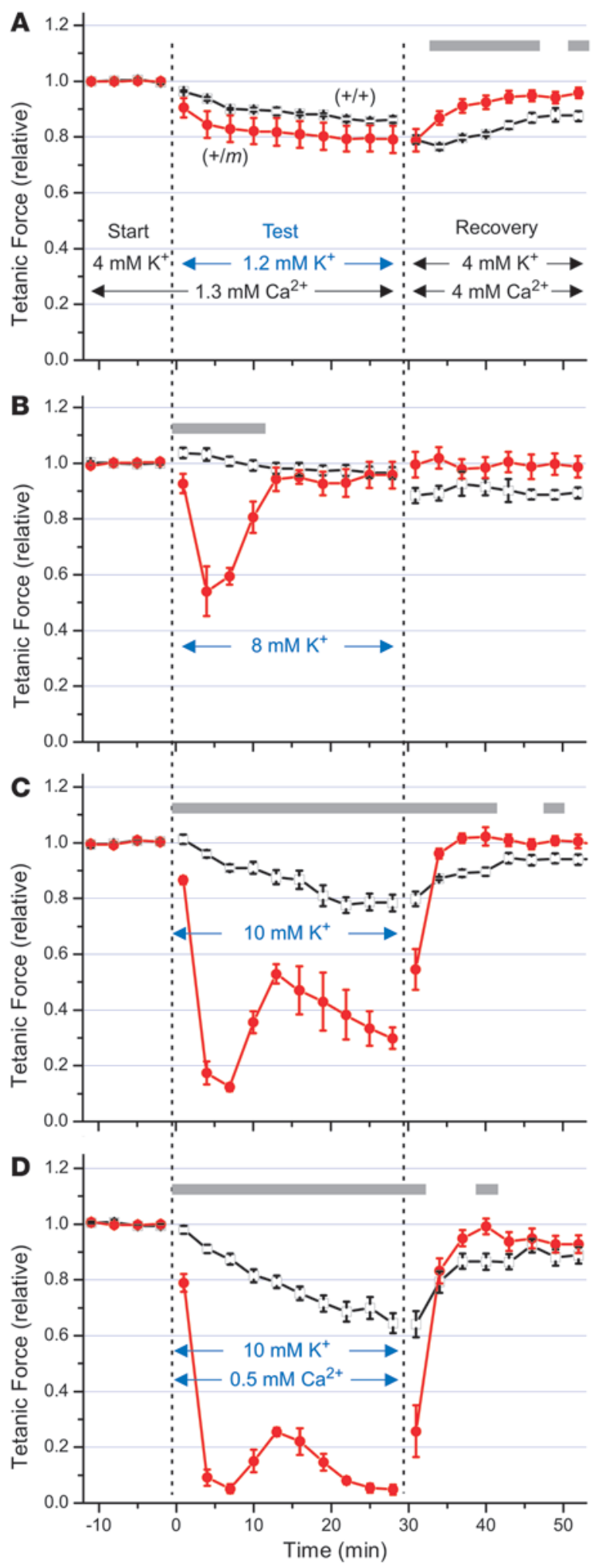

a preliminary experiment demonstrated that lowering $\left[\mathrm{Ca}^{2+}\right]_{0}$ to $0.5 \mathrm{mM}$ caused a significant decrease in mutant muscle force by itself and also intensified the effect of $8 \mathrm{mM}\left[\mathrm{K}^{+}\right]_{\mathrm{o}}$, as shown in Supplemental Figure 1. In Figure 6D, we observed that lowering $\left[\mathrm{Ca}^{2+}\right]_{0}$ to $0.5 \mathrm{mM}$ also exacerbated the weakness produced by

\section{Figure 6}

Raising $\left[\mathrm{K}^{+}\right]_{0}$ to $10 \mathrm{mM}$ produced sustained weakness that was greater for mutant $(+/ m)$ compared with normal $(+/+)$ EDL muscle. Isolated EDL muscles from $8.8 \pm 0.3$-month-old mutant mice or sibling controls were equilibrated for more than 30 minutes at $25^{\circ} \mathrm{C}$ in starting bath solution containing $4 \mathrm{mM}\left[\mathrm{K}^{+}\right]$and $1.3 \mathrm{mM}\left[\mathrm{Ca}^{2+}\right]$. Tetanic stimuli (0.5-ms, 70-mA current pulses for $300 \mathrm{~ms}$ at $125 \mathrm{~Hz}$ ) were applied every 3 minutes, and the peak tetanic responses (mean \pm SEM, $n=5-6$ for each group) are shown normalized to the starting values, $15.7 \pm 2.3 \mathrm{~g}$ for $(+/ \mathrm{m})$ and $18.4 \pm 0.6 \mathrm{~g}$ for $(+/+)$ muscle. Following each test condition, the bath was replaced with a recovery solution identical to the starting solution except containing approximately 3-fold higher $\left[\mathrm{Ca}^{2+}\right](4 \mathrm{mM})$ to help repolarize the membrane (37). (A) Lowering $\left[\mathrm{K}^{+}\right]_{0}$ to $1.2 \mathrm{mM}$ produced only mild force reduction that did not differ between mutant and control muscles. (B) Raising $\left[\mathrm{K}^{+}\right]_{\circ}$ to $8 \mathrm{mM}$ produced only transient weakness for mutant muscle, followed by recovery of force within 15 minutes. (C) Raising $\left[\mathrm{K}^{+}\right]_{\mathrm{o}}$ to $10 \mathrm{mM}$ caused pronounced and sustained weakness for mutant but not control muscle that was fully reversible in the recovery solution. (D) Lowering $\left[\mathrm{Ca}^{2+}\right]_{0}$ to $0.5 \mathrm{mM}$ exacerbated the weakness produced by elevated $\left[\mathrm{K}^{+}\right]_{\mathrm{o}}$. Gray bars indicate significant differences $(P<0.05$ by repeatedmeasures ANOVA with Bonferroni correction) between mutant (red circles) and control (open squares) responses.

raising $\left[\mathrm{K}^{+}\right]_{\mathrm{o}}$ to $10 \mathrm{mM}$ without affecting the time course of the triphasic response or the reversibility upon exposure to recovery solution. Overall, these results indicated that isolated mutant EDL exhibits an aberrant $\left[\mathrm{K}^{+}\right]$-induced weakness that can be modulated by ambient $\left[\mathrm{Ca}^{2+}\right]$ levels.

Increased sensitivity of mutant EDL to inbibition of the $\mathrm{Na}^{+} / \mathrm{K}^{+}$pump. Two-electrode voltage clamp studies of isolated flexor digitorum brevis fibers revealed a 30\% increase $(P<0.02)$ in the persistent $\mathrm{Na}^{+}$ current for heterozygous $(+/ m)$ fibers (data not shown). Because the high-capacity $\mathrm{Na}^{+} / \mathrm{K}^{+}$-ATPase pump in muscle contributes strongly toward maintaining the $\mathrm{Na}^{+}$and $\mathrm{K}^{+}$gradients required for normal muscle membrane excitability, we hypothesized that an abnormally increased $\mathrm{Na}^{+}$influx might render mutant muscle more vulnerable than control to partial inhibition of $\mathrm{Na}^{+} / \mathrm{K}^{+}$pump activity. In Figure 7A, the tetanic force elicited from EDL muscle in $4 \mathrm{mM}\left[\mathrm{K}^{+}\right]_{\mathrm{o}}$ and $1.3 \mathrm{mM}\left[\mathrm{Ca}^{2+}\right]_{\mathrm{o}}$ decreased by $31 \%$ for mutant compared with only $4 \%$ for control $(P<0.001)$ after exposure to $0.5 \mu \mathrm{M}$ ouabain for 15 minutes. Contraction of mutant EDL was nearly abolished after subsequent exposure to $2.0 \mu \mathrm{M}$ ouabain for 15 minutes, while control muscle force declined much more slowly $(P<0.001)$. Partial recovery of muscle force upon washout of ouabain occurred over 20 minutes for mutant EDL (Figure 7A) and for control (data not shown).

To test whether $\mathrm{Na}^{+} / \mathrm{K}^{+}$pump activity may have contributed to the force recovery observed during exposure to high $\left[\mathrm{K}^{+}\right]_{\mathrm{o}}$ in Figure $6, \mathrm{~B}$ and $\mathrm{C}$, we exposed EDL muscles to $0.5 \mu \mathrm{M}$ ouabain during challenge with $8 \mathrm{mM}\left[\mathrm{K}^{+}\right]_{\mathrm{o}}$ (Figure $7 \mathrm{~B}$ ) or $10 \mathrm{mM}\left[\mathrm{K}^{+}\right]_{\mathrm{o}}$ (Figure $7 \mathrm{C}$ ). Under these conditions, ouabain exacerbated the effects of high $\left[\mathrm{K}^{+}\right]_{\mathrm{o}}$ to reduce tetanic force. In $8 \mathrm{mM}\left[\mathrm{K}^{+}\right]_{\mathrm{o}}$, the mutant EDL force declined within 7 minutes by $73 \%$ with ouabain present (Figure $7 \mathrm{~B}$ ) compared with only a $46 \%$ decline with ouabain absent (Figure $6 \mathrm{~B}, P<0.01)$. We also observed a partial and transient recovery of force after 7 minutes (Figure 7B), as would be expected if increased intracellular $\mathrm{Na}^{+}$stimulated the total $\mathrm{Na}^{+} / \mathrm{K}^{+}$pump activity considerably above its basal level, despite partial inhibition of the pumps by ouabain. After 15 minutes, though, in contrast to the full recovery during $8 \mathrm{mM}\left[\mathrm{K}^{+}\right]_{0}$ that occurred in the absence of 

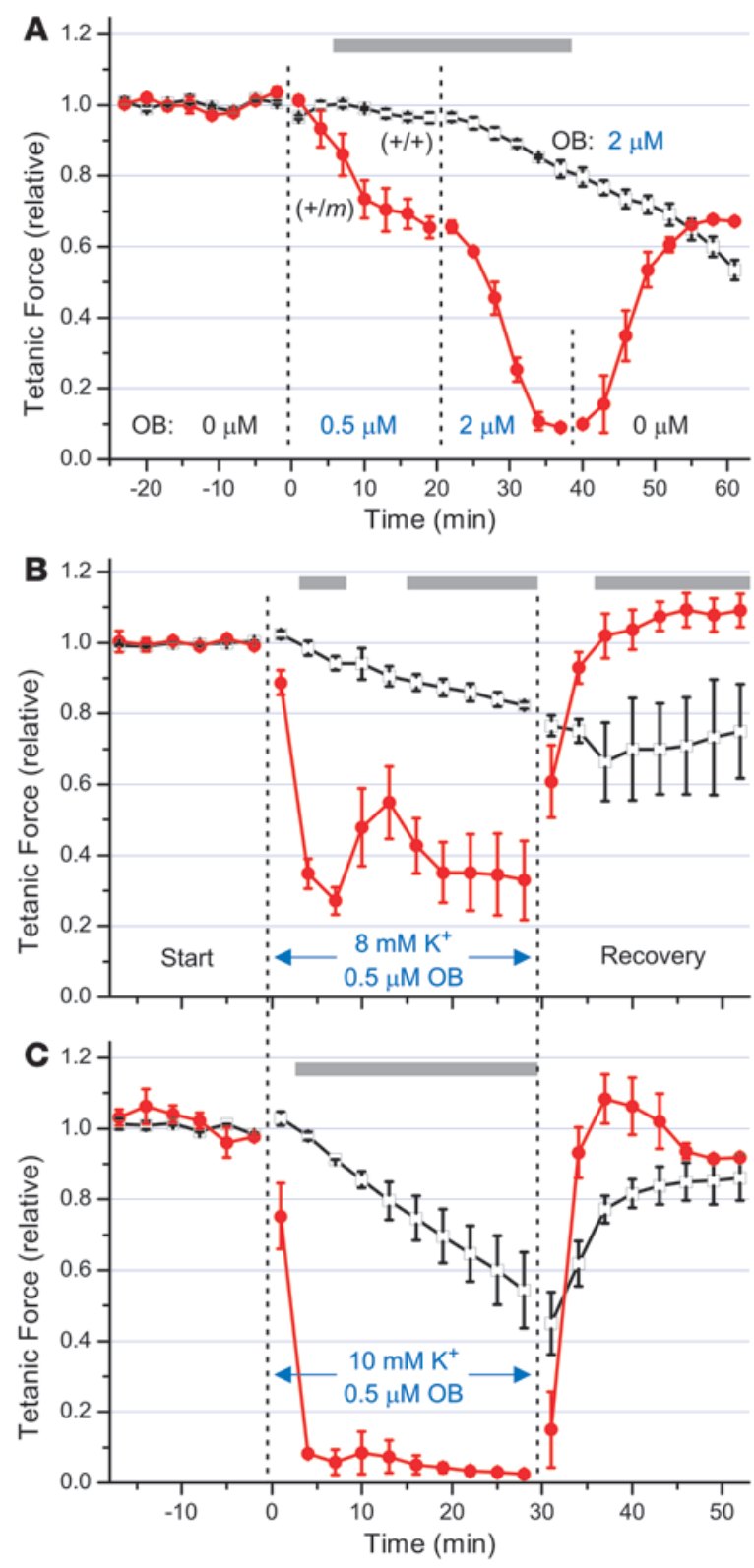

ouabain (Figure 6B), we observed an ongoing loss of force in the presence of ouabain (Figure $7 \mathrm{~B}$ ). This suggests that a high $\mathrm{Na}^{+} / \mathrm{K}^{+}$ pump capacity may be required to prevent sustained weakness of mutant muscle during challenge with $8 \mathrm{mM}\left[\mathrm{K}^{+}\right]_{\mathrm{o}}$.

Upon exposure to $10 \mathrm{mM}\left[\mathrm{K}^{+}\right]_{\mathrm{o}}$, we observed a dramatic initial decline in force for mutant EDL within 7 minutes whether ouabain was present or not (Figure 6C and Figure 7C). However, the partial rebound of tetanic force after 7 minutes (Figure 6C) was prevented in the presence of ouabain (Figure $7 C, P<0.05$ ). Overall, these findings suggest that a high $\mathrm{Na}^{+} / \mathrm{K}^{+}$pump capacity can significantly protect the mutant muscle from the consequences of extracellular $\mathrm{K}^{+}$challenge, probably by helping to maintain ionic homeostasis of $\mathrm{Na}^{+}$and $\mathrm{K}^{+}$and by its electrogenic effect to hyperpolarize the membrane. We also observed a more rapid restoration of force for mutant compared with control muscle during exposure to the recovery buffer (Figure 7, B and C), similar to that observed during the recovery in Figure 6.

\section{Figure 7}

Mutant $(+/ m)$ EDL was more sensitive than control $(+/+)$ muscle to inhibition of force by ouabain (OB), which also exacerbated the weakness produced by elevated $\left[\mathrm{K}^{+}\right]_{0}$. Isolated EDL muscles from $8.9 \pm 0.2-$ month-old mutant mice or sibling controls were equilibrated in bath containing $4 \mathrm{mM}\left[\mathrm{K}^{+}\right]_{\mathrm{o}}$ and $1.3 \mathrm{mM}\left[\mathrm{Ca}^{2+}\right]_{\mathrm{o}}$ and stimulated as in Figure 6; normalized peak tetanic responses (mean \pm SEM) are shown. (A) Mutant EDL was highly sensitive to $0.5-2.0 \mu \mathrm{M}$ ouabain, which affected control muscle much more slowly. (B) Adding $0.5 \mu \mathrm{M}$ ouabain greatly exacerbated the force reduction caused by raising $\left[\mathrm{K}^{+}\right]_{\mathrm{O}}$ to $8 \mathrm{mM}$ (compare Figure $6 \mathrm{~B}$ ) and produced sustained weakness. (C) Adding $0.5 \mu \mathrm{M}$ ouabain upon raising $\left[\mathrm{K}^{+}\right]_{\text {o }}$ to $10 \mathrm{mM}$ not only produced rapid paralysis that was reversible in the recovery solution but also nearly abolished the partial rebound that had occurred after 7 minutes in Figure 6C. Gray bars indicate significant differences by ANOVA $(P<0.05)$ between mutant (red circles) and control (open squares) responses. ANOVA was not determined in A during 40-60 minutes because the ouabain concentration was different for mutant $(0 \mu \mathrm{M})$ and control $(2 \mu \mathrm{M})$.

Slowed recovery of mutant EDL and susceptibility to delayed weakness after fatigue. Because ionic shifts of $\mathrm{Na}^{+}$and $\mathrm{K}^{+}$associated with the postexercise state may trigger paralytic attacks in HyperKPP, we next compared the properties of mutant and control muscles after continuous activity. Fatigue of isolated EDL muscles was induced by continuous $100-\mathrm{Hz}$ stimulation using 1 -ms pulses under baseline ionic conditions of $4 \mathrm{mM}\left[\mathrm{K}^{+}\right]_{\mathrm{o}}$ and $2 \mathrm{mM}\left[\mathrm{Ca}^{2+}\right]_{\mathrm{o}}$ at $25^{\circ} \mathrm{C}$. This produced a sustained contraction that began to weaken within several seconds (Figure $8 \mathrm{~A})$. In EDL muscle from older mice $(\sim 11$ months), the time required for decline to $50 \%$ of the peak force (fatigue $\mathrm{T}_{1 / 2 \mathrm{R}}$ ) was prolonged by 2.3 -fold $(P<0.001)$ for mutant compared with control, while in muscle from younger mice $(\sim 4$ months), the fatigue $T_{1 / 2 \mathrm{R}}$ was prolonged by 1.8 -fold $(P<0.001)$ for mutant compared with control (Figure 8A). The observed increase in resistance to continuous stimulation for EDL muscle expressing mutant $\mathrm{Na}_{V} 1.4$ was consistent with the shift of fast muscles toward a more oxidative phenotype (Figure 4).

We next compared the ability of mutant and control EDL muscles to recover from the fatigue produced by $100-\mathrm{Hz}$ stimulation (Figure $8 \mathrm{~B}$ ). Muscles from 8.5-month-old mice were first stimulated with 0.5 -ms current pulses every 3 minutes at $125 \mathrm{~Hz}$ for $0.3 \mathrm{sec}$ onds and equilibrated in a bath containing $4 \mathrm{mM}\left[\mathrm{K}^{+}\right]_{\mathrm{o}}$ and $2 \mathrm{mM}$ $\left[\mathrm{Ca}^{2+}\right]_{\mathrm{o}}$. Fatigue stimulation at $100 \mathrm{~Hz}$ for 50 seconds (Figure 8B, blue box) produced a decline in force to less than $5 \%$ of the starting value for all muscles (indicated by the symbols at $t=0$ ). The $\mathrm{T}_{1 / 2 \mathrm{R}}$ for entry into fatigue was $12.0 \pm 3.7$ seconds for mutant and $6.1 \pm 0.7$ seconds for control EDL (data not shown, $P<0.01$ ). When recovery proceeded in the same bath, the time required to regain $50 \%$ of the recovery amplitude from the fatigue-induced nadir (recovery $\left.\mathrm{T}_{1 / 2 \mathrm{R}}\right)$ was prolonged by 2.8 -fold $(P<0.01)$ for mutant compared with control muscle (Figure $8 \mathrm{~B}$ ). Much of this difference reflected a slower initiation of recovery for the mutant, since the recovery rate at its midpoint did not differ greatly between mutant $(9.3 \% \pm 2.1 \% / \mathrm{min})$ and control $(12.4 \% \pm 5.2 \% / \mathrm{min}, P=0.21)$. This was consistent with the longer period of contractile activity during the stimulation for mutant muscle, which should have produced greater intracellular accumulation of $\mathrm{Na}^{+}$and extracellular efflux of $\mathrm{K}^{+}$into the $\mathrm{t}$ tubules. Mutant muscle recovered fully in the bath containing normal $\left[\mathrm{K}^{+}\right]_{\mathrm{o}}$.

However, when the same induction of fatigue was followed by recovery in a bath containing $10 \mathrm{mM}\left[\mathrm{K}^{+}\right]_{\mathrm{o}}$ and $0.5 \mathrm{mM}\left[\mathrm{Ca}^{2+}\right]_{\mathrm{o}}$ to 

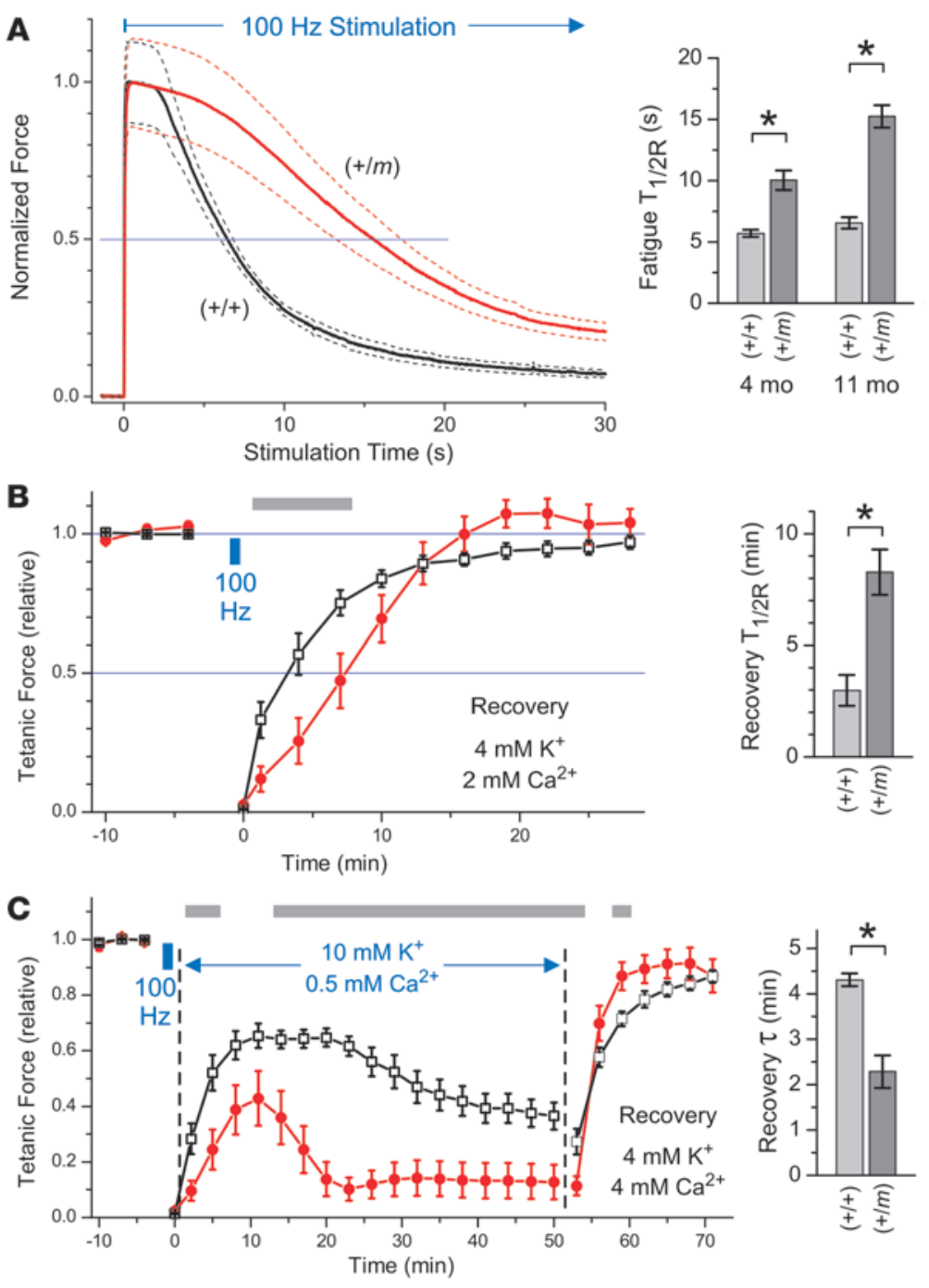

\section{Figure 8}

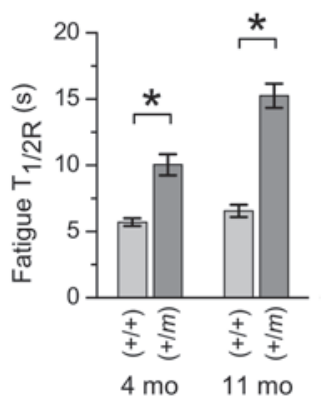

Mutant $(+/ m)$ EDL fatigued more slowly than control $(+/+)$ muscle and was more vulnerable to impaired recovery in elevated $\left[\mathrm{K}^{+}\right]_{0}$. (A-C) Fatigue was induced by continuous $100-\mathrm{Hz}$ stimulation to isolated EDL muscles using 1-ms pulses in bath that contained $4 \mathrm{mM}$ $\left[\mathrm{K}^{+}\right]$and $2 \mathrm{mM}\left[\mathrm{Ca}^{2+}\right]$. (A) In the left panel, tetanic force was normalized to the peak value, and the responses (mean $\pm \mathrm{SD}$, dashed lines) are shown for EDL from $(+/ m)$ mice $(n=8,10.8 \pm 2.2$ months old $)$ or $(+/+)$ mice ( $n=5,11.4 \pm 1.8$ months old). The time required for decline to $50 \%$ of the peak force (fatigue $\mathrm{T}_{1 / 2 \mathrm{R}}$ ) was increased by 2.3-fold for the older mutant mice versus controls and by 1.8-fold for younger mutant mice $(n=6$, $4.0 \pm 0.7$ months old) versus controls ( $n=10,4.2 \pm 0.8$ months old). (B) Recovery from fatigue for EDL muscles from $8.5 \pm 0.4-$ month-old mutant $(n=6)$ and sibling controls $(n=5)$ in normal $\left[\mathrm{K}^{+}\right]$. Tetanic stimuli (0.5-ms, 70-mA current pulses for $300 \mathrm{~ms}$ at $125 \mathrm{~Hz}$ ) were applied before and after $100-\mathrm{Hz}$ stimulation (small blue box), and the normalized responses (mean \pm SEM) are shown. The time required to regain $50 \%$ of the full extent of recovery (recovery $\mathrm{T}_{1 / 2 \mathrm{R}}$ ) was increased by 2.8-fold for mutant compared with control. (C) Stimulation of EDL muscles to fatigue as in $\mathbf{B}$ was followed by exposure to a bath containing $10 \mathrm{mM}\left[\mathrm{K}^{+}\right]$and $0.5 \mathrm{mM}$ $\left[\mathrm{Ca}^{2+}\right]$, which impaired the extent of recovery for mutant more than control muscles. Weakness was reversible in recovery buffer, and mutant muscles regained force 1.9-fold faster than did control muscle. Gray bars in the left panels indicate significant differences by ANOVA $(P<0.05)$ between mutant (red circles) and control (open squares) responses. The bar graphs in the right panels show mean \pm SEM. ${ }^{*} P<0.005$, 2-tailed Student's $t$ test. mimic a sustained elevation of interstitial $\left[\mathrm{K}^{+}\right]$during an attack of HyperKPP, the recovery of force was aborted after 10 minutes for mutant muscle and was followed by a sustained loss of force over the next 10 minutes (Figure $8 \mathrm{C}$ ). In contrast, although the recovery of control muscle was also impaired, the force began to decline slowly only after 20 minutes. The weakness in high $\left[\mathrm{K}^{+}\right]_{\mathrm{o}}$ was shown to be rapidly reversible upon exposure of the muscles to a recovery bath containing $4 \mathrm{mM}\left[\mathrm{K}^{+}\right]_{\mathrm{o}}$ and $4 \mathrm{mM}\left[\mathrm{Ca}^{2+}\right]_{\mathrm{o}}$ (Figure $8 \mathrm{C}$ ). The recovery of mutant and control muscle was fitted by a single exponential, and the recovery $\tau$ for the mutant was 1.9 -fold faster than for the control $(P<0.001)$. Overall, these results indicated that mutant EDL muscle recovers force more slowly after fatiguing stimulation and is more vulnerable to sustained weakness during recovery in elevated $\left[\mathrm{K}^{+}\right]_{\mathrm{o}}$ compared with control muscle.

\section{Discussion}

We observed several distinctive features in mice harboring a mutation in the gene encoding $\mathrm{Na}_{\mathrm{v}} 1.4$, corresponding to the human Met1592Val HyperKPP allele. First, skeletal muscle from $\mathrm{Na}_{\mathrm{V}} 1.4$ mutant mice showed prominent electrical myotonia, fiber type switching to a more oxidative phenotype, and myopathic changes related to gene dosage and age. Second, isolated EDL muscle from heterozygous mutant $(+/ m)$ animals developed less tetanic force and exhibited slower relaxation compared with muscle from wild type $(+/+)$ controls; these differences also increased with age. Third, rapid and sustained weakness of mutant EDL muscle was induced upon exposure to $10 \mathrm{mM}\left[\mathrm{K}^{+}\right]_{\mathrm{o}}$ that could be exacerbated by lowering $\left[\mathrm{Ca}^{2+}\right]_{\mathrm{o}}$ and by partial inhibition of the $\mathrm{Na}^{+} / \mathrm{K}^{+}$pump. Fourth, the weakness of mutant muscle was rapidly and fully reversed upon restoration of normal $\left[\mathrm{K}^{+}\right]_{\mathrm{o}}$ and elevation of $\left[\mathrm{Ca}^{2+}\right]_{\mathrm{o}}$. Fifth, mutant EDL muscle fatigued at a slower rate but also recovered more slowly than did normal muscle under control conditions; moreover, recovery was only partial at high $\left[\mathrm{K}^{+}\right]_{\mathrm{o}}$ and was followed by a second decrease in force that was sustained.

Chronic myotonia and activity-dependent changes in $\mathrm{Na}_{V} 1.4$ mutant muscle. Myotonia was clearly evident in $(+/ m)$ mutant mice, which parallels the frequent observation of interictal myotonia in human HyperKPP. The myotonia is most likely linked to persistent $\mathrm{Na}^{+}$ influx through the non-inactivating $\mathrm{Na}^{+}$channels for this mutant $(21,40)$ that mildly depolarizes the membrane and thereby increases excitability. We also obtained evidence for fiber damage with complete regeneration (fibers containing central nuclei) in $(+/ m)$ mice and fiber damage with incomplete regeneration (fibers containing striking vacuolar myopathy) in $(\mathrm{m} / \mathrm{m})$ mice that are 
characteristic of late-stage HyperKPP (7). The latter changes were accelerated in young $(\mathrm{m} / \mathrm{m})$ mice despite no spontaneous bouts of episodic paralysis.

A shift in the fiber type composition toward more oxidative type IIA fibers is consistent with the effect of continuous muscular activity produced by chronic stimulation (31) and would also be expected from the myotonic activity observed in this study. Gene expression in specific fiber types is coordinately controlled by transcription factors (31). One of these factors, PGC- $1 \alpha$, increases oxidative capacity in muscles and was upregulated in mutant tibialis anterior muscle (Figure 4G). Thus, the muscle from mutant mice and HyperKPP share a myotonic phenotype, and the resulting shift in fiber type and upregulation of at least one transcription factor are consistent with the expected consequences of chronic muscle activity.

The decrease in twitch and tetanic force concomitant with slower relaxation for mutant compared with control EDL further suggested that the contractile characteristics were shifted toward those of a slow-twitch muscle like soleus, which generates less force and relaxes more slowly than normal EDL (41). It is important to note, however, that the decrease in force generation with aging in the mutant mice may also be in part related to the increased number of damaged fibers. Regardless of the mechanism for the lower force, it is analogous to the clinical observation of increasing fixed weakness (or lower force generation) with age in HyperKPP patients $(10,14)$ and supports the notion that myopathy may depend on factors besides the paralytic episodes (13).

Elevated $\left[\mathrm{K}^{+}\right]_{\text {o }}$ produced sustained weakness of isolated mutant EDL muscle. Individuals with HyperKPP typically develop profound weakness when venous $\left[\mathrm{K}^{+}\right]$is only $4.5-6.5 \mathrm{mM}$, and the venous $\left[\mathrm{K}^{+}\right]$can remain normal $(3.5-5.0 \mathrm{mM})$ in up to $50 \%$ of individuals during paralytic episodes $(14,42)$. The original "normokalemic" periodic paralysis family described by Poskanzer and Kerr (43) and subsequently shown to harbor the Met1592Val mutation in the $\mathrm{Na}_{V} 1.4$ gene (42), showed a sensitivity to oral ingestion of $\mathrm{K}^{+}$even though the plasma $\left[\mathrm{K}^{+}\right]$remained in the normal range during attacks. The phenotype associated with the Met1592Val mutation can be heterogeneous, though, with other reports indicating attacks of weakness associated with mild hyperkalemia or with cold sensitivity $(44,45)$. We observed that raising $\left[\mathrm{K}^{+}\right]_{\mathrm{o}}$ from 4 to $8 \mathrm{mM}$ produced only transient weakness in isolated mutant EDL muscle. In contrast, raising $\left[\mathrm{K}^{+}\right]_{\mathrm{o}}$ to $10 \mathrm{mM}$ produced a sustained weakness of mutant EDL at $25^{\circ} \mathrm{C}$ that was significantly greater than that produced in wild-type EDL. Although the $\left[\mathrm{K}^{+}\right]_{\mathrm{o}}$ levels in our experiments are much higher than those in venous plasma during a paralytic attack, it is important to note that during knee-extension exercise in humans, femoral venous $\left[\mathrm{K}^{+}\right]$reaches $5.9-6.8 \mathrm{mM}$, while muscle interstitial $\left[\mathrm{K}^{+}\right]$ exceeds $10 \mathrm{mM}$ (46). Considering the smaller size of t tubules, one can expect even higher t-tubular $\left[\mathrm{K}^{+}\right]$, especially during myotonic activity as occurs in HyperKPP muscles. The mutant mice therefore appear to reproduce one of the hallmarks of HyperKPP: an increased sensitivity to locally elevated $\left[\mathrm{K}^{+}\right]$.

$\left[\mathrm{Ca}^{2+}\right]_{0}$ modulation of the HyperKPP phenotype. Although a large derangement of plasma $\left[\mathrm{Ca}^{2+}\right]$ does not occur during attacks of HyperKPP (47), intravenous administration of calcium gluconate helps to counteract the weakness $(5,6)$. It was therefore not surprising to observe an increased sensitivity to $\left[\mathrm{Ca}^{2+}\right]_{0}$ in mutant EDL. First, lowering $\left[\mathrm{Ca}^{2+}\right]_{0}$ to $0.5 \mathrm{mM}$ produced transient weakness in mutant but not in normal EDL (Supplemental Figure 1). Second, low $\left[\mathrm{Ca}^{2+}\right]_{\mathrm{o}}$ exacerbated the weakness caused by high $\left[\mathrm{K}^{+}\right]_{\mathrm{o}}$ to a greater extent in mutant than in control EDL (Figure 6). Third, raising $\left[\mathrm{Ca}^{2+}\right]_{\mathrm{o}}$ to $4 \mathrm{mM}$ improved force recovery upon restoration of normal $\left[\mathrm{K}^{+}\right]_{\mathrm{o}}$, being greater and faster in mutant than in normal EDL. Thus, mice expressing the mutant allele reproduce another characteristic of HyperKPP, namely the increased $\mathrm{Ca}^{2+}$ sensitivity manifested by an improvement of muscle function following venous infusion of $\mathrm{Ca}^{2+}$. The mechanism by which altered $\left[\mathrm{Ca}^{2+}\right]_{\mathrm{o}}$ modulates susceptibility to $\mathrm{K}^{+}$-induced paralysis in $(+/ m)$ muscle has not been elucidated but may involve either direct effects on $\mathrm{Na}_{V}$ channel gating (48) or an indirect effect related to neutralization of negative surface charges (49). The effects of $\mathrm{Ca}^{2+}$ observed in this study are also consistent with the observation that in normal muscle fibers, increased $\left[\mathrm{Ca}^{2+}\right]_{\mathrm{o}}$ hyperpolarizes the resting membrane potential (36) and restores force in the presence of high $\left[\mathrm{K}^{+}\right]_{\mathrm{o}}$ (37). It remains to be determined whether similar mechanisms are involved in the mutant EDL muscle.

Relevance of $\mathrm{Na}^{+} / \mathrm{K}^{+}$pump activity to protection from weakness in HyperKPP. In human HyperKPP muscle, weakness induced by raising $\left[\mathrm{K}^{+}\right]_{\mathrm{o}}$ to $10 \mathrm{mM}$, exercise, or cold exposure is associated with increased intracellular $\left[\mathrm{Na}^{+}\right]\left(\left[\mathrm{Na}^{+}\right]_{\mathrm{i}}\right)(16,45)$. Increased $\left[\mathrm{Na}^{+}\right]_{\mathrm{i}}$ is an important factor for activation of the $\mathrm{Na}^{+} / \mathrm{K}^{+}$pump $(50,51)$, and $\mathrm{Na}^{+} / \mathrm{K}^{+}$pump stimulation improves membrane excitability and contractility in normal muscles with reduced $\mathrm{Na}^{+}$and/or $\mathrm{K}^{+}$ gradients (52-54). We observed that partial inhibition of the pump with $0.5 \mu \mathrm{M}$ ouabain exacerbated the $\mathrm{K}^{+}$effect on EDL muscle and drastically reduced the transient recovery observed at high $\left[\mathrm{K}^{+}\right]_{\mathrm{o}}$. These effects are most likely due to (a) a greater increase in $\left[\mathrm{Na}^{+}\right]_{i}$ concomitant with (b) incremental depolarization of the cell membrane $(55,56)$, further suggesting that disturbances in $\left[\mathrm{Na}^{+}\right]_{\mathrm{i}}$ and membrane potentials are important mechanisms involved in the weakness in HyperKPP. A potential role of the $\mathrm{Na}^{+} / \mathrm{K}^{+}$pump is also in agreement with the fact that stimulation of the pump with mild exercise, $\beta 2$-adrenergic agonists, or insulin improves muscle function in HyperKPP $(5,9,12,25,47)$.

Recovery from fatigue and its possible link to attacks triggered by the postexercise state. T-tubular $\mathrm{K}^{+}$accumulation and increased $\left[\mathrm{Na}^{+}\right]_{\mathrm{i}}$ are 2 major factors contributing to the decrease in force during muscle fatigue (57). Considering the greater $\mathrm{K}^{+}$sensitivity in mutant EDL, it might be predicted that mutant muscle would fatigue more rapidly than normal muscle. However, the opposite was observed: mutant EDL was more fatigue resistant, especially in older animals. Two factors related to the observed fiber type switching may have contributed to this increased resistance to fatigue. First, the combination of greater oxidative capacity plus lower energy demand because of lower force production in mutant EDL may have overridden the depressing effect of $\mathrm{K}^{+}$. Second, the $\mathrm{Na}^{+}$influx and $\mathrm{K}^{+}$ efflux during action potentials are much smaller in the slow-twitch soleus muscle than in the fast-twitch EDL (58). It is therefore possible that the mutant EDL has lower $\mathrm{Na}^{+}$and $\mathrm{K}^{+}$fluxes associated with action potentials than does the normal EDL.

Events observed during the recovery period after fatigue in EDL muscles provided insights especially relevant to HyperKPP. Attacks of episodic weakness in HyperKPP do not happen during or immediately following exercise. Rather, they typically occur during rest approximately 30 minutes after strenuous activity, for reasons that remain unclear. Mutant EDL muscle required a slightly longer time than normal EDL to recover fully from fatigue in normal $\left[\mathrm{K}^{+}\right]_{\mathrm{o}}$, whereas, at $10 \mathrm{mM}\left[\mathrm{K}^{+}\right]_{\mathrm{o}}$, the recovery in mutant EDL was aborted after approximately 10 minutes, and sustained weakness ensued. This appears analogous to the delayed weakness observed after exercise in individuals with HyperKPP. 
In conclusion, knock-in mice expressing the human Met1592Val mutation in the gene encoding $\mathrm{Na}_{\mathrm{V}} 1.4$ exhibit several hallmarks of the HyperKPP phenotype. These include: myotonic activity in vivo, increased myofiber damage, increased sensitivity to elevated $\left[\mathrm{K}^{+}\right]_{\mathrm{o}}$ resulting in profound weakness, increased capacity to recover from $\mathrm{K}^{+}$-induced weakness upon increasing $\left[\mathrm{Ca}^{2+}\right]_{\mathrm{o}}$, and apparent weakness following fatigue when the recovery occurs at elevated $\left[\mathrm{K}^{+}\right]_{\mathrm{o}}$. Moreover, this study provides several new mechanistic insights relevant to the pathophysiology of HyperKPP. First, we have shown that induction of sustained muscle weakness requires a local elevation of $\left[\mathrm{K}^{+}\right]_{\mathrm{o}}$ to a level that exceeds the serum $\left[\mathrm{K}^{+}\right]$ attained during attacks. Second, we have demonstrated a modulatory effect of $\left[\mathrm{Ca}^{2+}\right]$ on $\mathrm{K}^{+}$-induced weakness that extends beyond the clinical observation of improvement with calcium gluconate. Third, we have shown an increased susceptibility to paralysis when $\mathrm{Na}^{+} / \mathrm{K}^{+}$pump function is impaired by ouabain, which is consistent with the hypothesis that pump stimulation linked to moderate muscle activity may be protective against attacks. Fourth, we have shown that increased mutant gene dosage has the dramatic effect of accelerating the myopathic process, which can be dissociated from attacks of episodic weakness. Fifth, we have shown that impaired recovery from fatigue may contribute to the curious delay ( $\sim 30$ minutes) between provocative exercise and onset of weakness in human HyperKPP.

Previous studies to define the consequences of mutant $\mathrm{Na}$ channels in resealed cut human muscle fibers have allowed only limited measurements to be performed using scarce material. We suggest that this mutant mouse is a reasonable animal model for more comprehensive pathophysiological studies of HyperKPP that can be performed on intact muscle with a common genetic background. Future investigations will employ this model to (a) facilitate investigation of mechanisms that trigger myotonia and paralytic attacks in vivo, (b) provide a tissue source for in vitro studies of affected muscle, (c) contribute to clarifying the relation between chronic myofiber hyperactivity and vacuolar myopathy, and (d) provide a system to develop more effective treatments for HyperKPP and related diseases.

\section{Methods}

Mice. Mutant $\mathrm{Na}_{v} 1.4$ knock-in mice were generated as detailed in Supplemental Methods at the Massachusetts General Hospital Knock-in Mouse Core facility directed by En Li. The line was bred into the C56BL/6J background for more than 4 generations and has been designated B6.129S4$\operatorname{Scn} 4 a^{t m 1 L j b}$. All procedures were conducted under protocols approved by the Institutional Animal Care and Use Committees at Massachusetts General Hospital and the University of Massachusetts Medical School in accordance with the Animal Welfare Act and the Department of Health and Human Services.

Southern blotting. Genomic DNA was digested as indicated, run on $0.8 \%$ agarose gels, and transferred to nylon membranes using standard protocols. Prehybridization was at $45^{\circ} \mathrm{C}$ for 2 hours in buffer A, containing $2.8 \times$ SSPE, $50 \%$ formamide, $5 \times$ Denhardt's, and $50 \mu \mathrm{g} / \mathrm{ml}$ denatured salmon sperm DNA. DNA probes were labeled with [ $\left.{ }^{32} \mathrm{P}\right] \mathrm{dGTP}$ using the Random Primed DNA Labeling Kit (Boehringer) and added at $2 \times 10^{6} \mathrm{cpm} / \mathrm{ml}$ to buffer $\mathrm{A}$. Blots were hybridized overnight at $42^{\circ} \mathrm{C}$, washed 4 times at $50^{\circ} \mathrm{C}$ with increasing stringency (final $0.2 \times$ SSC plus $1 \%$ SDS), and bands were visualized by autoradiography.

Total RNA isolation and RT-PCR. Flash-frozen skeletal muscle, heart, and brain tissues (100-200 $\mathrm{mg}$ ) from $(+/+)$ and $(+/ \mathrm{m})$ mice were homogenized in $2 \mathrm{ml}$ of TRIzol (Gibco BRL) using a Polytron PT 10-35 homogenizer
(Kinematica AG). The homogenized samples were incubated for 5 minutes at room temperature and centrifuged at $12,000 \mathrm{~g}$ for 10 minutes at $4^{\circ} \mathrm{C}$. The upper phase was extracted with $0.4 \mathrm{ml}$ of chloroform for 15 seconds, incubated at room temperature for 3 minutes, and centrifuged at $12,000 \mathrm{~g}$ for 15 minutes at $4^{\circ} \mathrm{C}$. The upper aqueous phase was mixed with $1 \mathrm{ml}$ of isopropyl alcohol, incubated at room temperature for 10 minutes, and centrifuged at $12,000 \mathrm{~g}$ at $4^{\circ} \mathrm{C}$ for 10 minutes. The pellet was washed with $2 \mathrm{ml}$ of $75 \%$ ethanol by centrifuging at 7,500 $\mathrm{g}$ for 5 minutes at $4^{\circ} \mathrm{C}$. The RNA pellet was air dried for 10 minutes and resuspended in RNase-free $\mathrm{H}_{2} \mathrm{O}$.

For first-strand cDNA synthesis for RT-PCR, $1.5 \mu \mathrm{g}$ of total RNA and $2 \mu \mathrm{l}$ of random decamers (50 $\mu \mathrm{M}$; Ambion) were adjusted to $12 \mu \mathrm{l}$ with RNase-free $\mathrm{H}_{2} \mathrm{O}$ and heated to $80^{\circ} \mathrm{C}$ for 3 minutes to denature the RNA. The RNA-primer mixture was chilled on ice and centrifuged briefly. The remaining components for reverse transcription were added, including $2 \mu \mathrm{l}$ of $10 \times$ first-strand buffer $\left(500 \mathrm{mM} \mathrm{KCl}, 15 \mathrm{mM} \mathrm{MgCl}_{2}\right.$, and $100 \mathrm{mM}$ Tris-HCl, pH 8.3), $4 \mu \mathrm{l}$ of dNTP mix (2.5 mM each dNTP), $1 \mu$ l of RNase inhibitor (10 U/ $\mu \mathrm{l}$; Ambion), and $1 \mu \mathrm{l}$ of MMLV-RT (100 U/ $\mu \mathrm{l}$; Ambion). The reaction was incubated for 60 minutes at $42^{\circ} \mathrm{C}$ followed by 10 minutes at $92^{\circ} \mathrm{C}$ to inactivate the reverse transcriptase. PCR was performed as above for amplification of genomic DNA using the standard protocol, except that the reaction contained $4 \mu \mathrm{l}$ of reverse transcription products as template, and the annealing temperature was $60^{\circ} \mathrm{C}$. For the RT-PCR in Figure 2B, the template primers were (c) mSk757F, $5^{\prime}$-TACTACTTCACCATTGGCTGGAATATCTTCGACTTCG-3' at the $3^{\prime}$ end of exon 23 and (b) mSk998R, $5^{\prime}$-CTGAGCACAATCTCCATTTCCCTCAGC-3' in the $3^{\prime}$-UTR of exon 24. This produced a $1.43-\mathrm{kb}$ DNA product amplified only from cDNA that was digested with $H p a \mathrm{I}$ or NspI as above.

Northern blotting. Total RNA $(5 \mu \mathrm{g})$ from mouse tissues was denatured for 15 minutes at $65^{\circ} \mathrm{C}$ in 3 volumes of formaldehyde load dye (Ambion) and separated on a $1 \%$ formaldehyde agarose gel (NorthernMax; Ambion). The RNAs were transferred to nylon membrane, crosslinked, and prehybridized in UltraHyb buffer (Ambion) for more than 30 minutes at $42^{\circ} \mathrm{C}$. The mSkE24 DNA probe was labeled with ${ }^{32} \mathrm{P}$, denatured for 10 minutes at $95^{\circ} \mathrm{C}$, chilled for 5 minutes on ice, added into UltraHyb buffer, and incubated with the blot for $16-24$ hours at $42^{\circ} \mathrm{C}$. The blot was washed with low-and high-stringency wash solutions (Ambion) at $42^{\circ} \mathrm{C}$ and exposed to BioMax MR film (Kodak). Hybridization of a GAPDH probe (Ambion) was similarly performed after probe removal using the Strip-EZ DNA kit (Ambion).

Antibodies. Primary antibodies included a monoclonal antibody generously provided by Susan D. Kraner (University of Kentucky, Lexington, Kentucky, USA) (L/D3, dilution 1:30), which specifically recognizes Nav1.4 (19); a rabbit polyclonal antibody that recognizes the C terminus of PGC- $1 \alpha$ (AB3242, Chemicon; dilution 1:1,000) (59); and a rabbit polyclonal antibody that recognizes GAPDH (ab9485, Abcam; dilution 1:2,000). Secondary antibodies were HRP-conjugated reagents from Amersham (dilution 1:1,000) that included rabbit anti-mouse Ig (NIF 825) or donkey anti-rabbit Ig (NA 934). The A4.74 monoclonal antibody developed by H. M. Blau that specifically recognizes myosin in type IIA fatigue-resistant fast-twitch fibers (35) was obtained from the Developmental Studies Hybridoma Bank developed under the auspices of the NICHD and maintained by the University of Iowa, Department of Biological Sciences, Iowa City, Iowa, USA.

Protein isolation and Western blotting. Membrane protein fractions (Figure 2C) were obtained by disruption of $0.2 \mathrm{~g}$ of frozen tissue using a Polytron homogenizer for 30-60 seconds on ice in a 70-fold (wt/wt) excess of lysis buffer ( $\mathrm{pH}$ 7.6) that contained $0.25 \mathrm{M}$ sucrose, $100 \mathrm{mM}$ Tris, $10 \mathrm{mM}$ EDTA, $10 \mathrm{mM}$ EGTA, and $1 \times$ protease inhibitor cocktail (Complete; Roche). The mixture was centrifuged at $1,900 \mathrm{~g}$ for 5 minutes at $4^{\circ} \mathrm{C}$, and the supernatant was collected and spun further at $22,000 \mathrm{~g}$ for 30 minutes at $4^{\circ} \mathrm{C}$. The pellet was resuspended in $0.8 \mathrm{ml}$ of water, $40 \mu \mathrm{l}$ of $20 \%$ SDS was added, and the mixture was heated for 20 minutes at $65^{\circ} \mathrm{C}$. 
Soluble proteins (Figure 4G) were obtained by disruption of frozen tissues at $4^{\circ} \mathrm{C}$ in a 10 -fold (wt/wt) excess of lysis buffer $(\mathrm{pH} 7.6)$ that contained $8.7 \mathrm{mMNaH}_{2} \mathrm{PO}_{4}, 58 \mathrm{mM} \mathrm{Na}_{2} \mathrm{HPO}_{4}, 144 \mathrm{mM} \mathrm{NaCl}, 1 \% \mathrm{NP}-40,0.5 \%$ sodium deoxycholate, $0.1 \%$ SDS, and $1 \times$ protease inhibitor cocktail, using a PRO 200 homogenizer (PRO Scientific). Samples were centrifuged at $22,000 \mathrm{~g}$ for 10 minutes at $4^{\circ} \mathrm{C}$, and the final supernatant after 2 spins was collected. All proteins were stored as aliquots at $-80^{\circ} \mathrm{C}$, and concentrations were determined by the BCA assay (Pierce).

For Western blots, proteins were resolved on 7.5\% SDS-PAGE and electroblotted to PVDF membranes. The membrane was blocked with $1 \%$ nonfat milk in $137 \mathrm{mM} \mathrm{NaCl}, 2.7 \mathrm{mM} \mathrm{KCl}, 25 \mathrm{mM}$ Tris-HCl (TBS, pH 7.4) for 30 minutes, followed by addition of primary antibody and incubation with gentle rocking overnight at $40^{\circ} \mathrm{C}$ (or 2 hours at room temperature for the L/D3 antibody). Blots were washed 3 times for 5 minutes each with TBS plus $0.1 \%$ Tween- 20 (TBS-T) and then incubated with the appropriate secondary antibody (dilution 1:1,000) in blocking solution for 60 minutes at room temperature. After 3 washes for 5 minutes each with TBS-T, the immunoreactive proteins were visualized by detection of HRP-catalyzed chemiluminescence (ECL kit; Amersham) and imaged using a Kodak ImageStation $440 \mathrm{CF}$. Protein bands were quantitated using ImageJ software (http://rsb.info.nih.gov/ij/).

Muscle staining. Standard protocols were used to stain $10-\mu \mathrm{m}$ muscle sections using H\&E, SDH, and the A4.74 antibody, as detailed in Supplemental Methods.

Electromyography. Mice were anesthetized with $40 \mathrm{mg} / \mathrm{kg}$ sodium pentobarbital by intraperitoneal injection. Surface temperature was monitored throughout the experiment and kept above $30^{\circ} \mathrm{C}$ by using a heated pad underneath the mouse and a heat lamp above the mouse. Spontaneous electrical activity of hind-limb muscles was recorded using $25-\mathrm{mm}$ bipolar concentric needles (Oxford Instruments) and a ground electrode taped to the tail.

Muscle twitch force measurements. Mice were anesthetized with isoflurane by inhalation and killed by cervical dislocation. The EDL muscle was dissected and mounted vertically in a $25-\mathrm{ml}$ organ bath (World Precision Instruments). The starting bath solution for Figure 5, Figure 8A, and Supplemental Figure 1 contained (in $\mathrm{mM}$ ): $118 \mathrm{NaCl}, 25 \mathrm{NaHCO}_{3}, 2.82$ $\mathrm{KCl}, 1.18 \mathrm{KH}_{2} \mathrm{PO}_{4}, 1.18 \mathrm{MgSO}_{4}, 2.0 \mathrm{CaCl}_{2}, 10$ glucose, insulin (Humulin U-100; Lilly; $20 \mathrm{U} / \mathrm{l})$, and D-tubocurarine chloride $(0.25 \mu \mathrm{M})$ and was bubbled continuously with $95 \% \mathrm{O}_{2}, 5 \% \mathrm{CO}_{2}$. The bath temperature was maintained at $25^{\circ} \mathrm{C}$ to prolong muscle viability. The muscles were adjusted to their optimal preload length to produce maximal tetanic contraction, and insulin and curare were removed after 30 minutes, followed by a further 30 minutes of equilibration. For Figure 6, Figure 7, and Figure 8, B and C, the baseline bath contained (in $\mathrm{mM}$ ): $122.2 \mathrm{NaCl}, 25 \mathrm{NaHCO}_{3}, 2.8 \mathrm{KCl}, 1.2$ $\mathrm{KH}_{2} \mathrm{PO}_{4}, 1.2 \mathrm{MgSO}_{4}, 1.3 \mathrm{CaCl}_{2}$, and 5 glucose, with any changes from this noted in the text; muscles were not exposed to insulin or curare. For some measurements, the bath solution was exchanged with solutions containing altered $[\mathrm{KCl}]$ or $\left[\mathrm{CaCl}_{2}\right]$; whenever $\mathrm{CaCl}_{2}$ was lowered, the divalent cation concentration was kept constant by adding equimolar $\mathrm{MgCl}_{2}$. Single 50- to 70 -mA current pulses (0.5- or 1-ms duration) or tetanic stimuli (pulses at 20,50,100, or $125 \mathrm{~Hz}$ ) were applied via platinum wires spaced $2.7 \mathrm{~mm}$ apart. Isometric contractile responses were recorded using a force transducer, acquired at $2 \mathrm{kHz}$, and analyzed using PClamp9 (Axon), Origin (MicroCal), and StatView (SAS) software.

Statistics. Data are presented as mean \pm SEM unless otherwise indicated. Two-tailed Student's $t$ test was used to compare the means between 2 groups. The temporal responses in Figures 6-8 were compared by repeatedmeasures ANOVA followed by Bonferroni's post-hoc test. Significance was accepted for $P<0.05$.

\section{Acknowledgments}

This study was supported by the Muscular Dystrophy Association (L.J. Hayward, S.C. Cannon); NIH grants K08 NS01990 (to L.J. Hayward) and R01 AR042703 (to S.C. Cannon); and the Cecil B. Day Neuromuscular Research Laboratory (R.H. Brown). We thank Thomas Smith and David Chad for stimulating discussions and constructive criticism, Molly Kidder for assistance with the experiments shown in Figures 6-8, Jane Sargent for assistance with electromyography for Supplemental Videos 1 and 2, T. J. Ley for the plasmid p1338, and Susan D. Kraner for the L/D3 antibody.

Received for publication May 9, 2007, and accepted in revised form January 16, 2008.

Address correspondence to: Lawrence J. Hayward, University of Massachusetts Medical School, 55 Lake Avenue North, Worcester, Massachusetts 01655, USA. Phone: (508) 856-4147; Fax: (508) 8566778; E-mail: lawrence.hayward@umassmed.edu.

Ming-Yang Lee's present address is: Neurosurgical Division, Department of Surgery, National Cheng-Kung University Hospital, Tainan, Republic of China.
1. Lehmann-Horn, F., Rudel, R., and Jurkat-Rott, K. 2004. Nondystrophic myotonias and periodic paralyses. Myology. A.G. Engel and C. Franzini-Armstrong, editors. 3rd edition. McGraw-Hill. New York, New York, USA. 1257-1300.

2. Cannon, S.C. 2006. Pathomechanisms in channelopathies of skeletal muscle and brain. Annu. Rev. Neurosci. 29:387-415.

3. Creutzfeldt, O.D., Abbott, B.C., Fowler, W.M., and Pearson, C.M. 1963. Muscle membrane potentials in episodic adynamia. Electroencephalogr. Clin. Neurophysiol. 15:508-519.

4. Tyler, F.H., Stephens, F.E., Gunn, F.D., and Perkoff, G.T. 1951. Studies in disorders of muscle. VII. Clinical manifestations and inheritance of a type of periodic paralysis without hypopotassemia. J. Clin. Invest. 30:492-502.

5. Gamstorp, I., Hauge, M., Helweglarsen, H.F., Mjones, H., and Sagild, U. 1957. Adynamia episodica hereditaria: a disease clinically resembling familial periodic paralysis but characterized by increasing serum potassium during the paralytic attacks. Am. J. Med. 23:385-390.

6. Van Der Meulen, J.P., Gilbert, G.J., and Kane, C.A.
1961. Familial hyperkalemic paralysis with myotonia. N. Engl. J. Med. 264:1-6.

7. Pearson, C.M. 1964. The periodic paralyses: differential features and pathological observations in permanent myopathic weakness. Brain. 87:341-354.

8. Streeten, D.H., Dalakos, T.G., and Fellerman, H. 1971. Studies on hyperkalemic periodic paralysis. Evidence of changes in plasma $\mathrm{Na}$ and $\mathrm{Cl}$ and induction of paralysis by adrenal glucocorticoids. J. Clin. Invest. 50:142-155.

9. Clausen, T., Wang, P., Orskov, H., and Kristensen, O. 1980. Hyperkalemic periodic paralysis. Relationships between changes in plasma water, electrolytes, insulin and catecholamines during attacks. Scand. J. Clin. Lab. Invest. 40:211-220.

10. Miller, T.M., et al. 2004. Correlating phenotype and genotype in the periodic paralyses. Neurology. 63:1647-1655.

11. Tawil, R., et al. 2000. Randomized trials of dichlorphenamide in the periodic paralyses. Working Group on Periodic Paralysis. Ann. Neurol. 47:46-53.

12. Wang, P., and Clausen, T. 1976. Treatment of attacks in hyperkalaemic familial periodic paralysis by inhalation of salbutamol. Lancet. 1:221-223.
13. Bradley, W.G., et al. 1990. Progressive myopathy in hyperkalemic periodic paralysis. Arch. Neurol. 47:1013-1017.

14. Plassart, E., et al. 1994. Mutations in the muscle sodium channel gene (SCN4A) in 13 French families with hyperkalemic periodic paralysis and paramyotonia congenita: phenotype to genotype correlations and demonstration of the predominance of two mutations. Eur. J. Hum. Genet. 2:110-124.

15. Lehmann-Horn, F., et al. 1983. Two cases of adynamia episodica hereditaria: in vitro investigation of muscle cell membrane and contraction parameters. Muscle Nerve. 6:113-121.

16. Lehmann-Horn, F., et al. 1987. Adynamia episodica hereditaria with myotonia: a non-inactivating sodium current and the effect of extracellular $\mathrm{pH}$. Muscle Nerve. 10:363-374.

17. Fontaine, B., et al. 1990. Hyperkalemic periodic paralysis and the adult muscle sodium channel alpha-subunit gene. Science. 250:1000-1002.

18. Rojas, C.V., et al. 1991. A Met-to-Val mutation in the skeletal muscle $\mathrm{Na}+$ channel alpha-subunit in hyperkalaemic periodic paralysis. Nature. 354:387-389.

19. Kraner, S.D., Tanaka, J.C., and Barchi, R.L. 1985. 
Purification and functional reconstitution of the voltage-sensitive sodium channel from rabbit T-tubular membranes. J. Biol. Chem. 260:6341-6347.

20. Cummins, T.R., and Sigworth, F.J. 1996. Impaired slow inactivation in mutant sodium channels. Biophys. J. 71:227-236.

21. Hayward, L.J., Brown, R.H., Jr., and Cannon, S.C. 1997. Slow inactivation differs among mutant $\mathrm{Na}$ channels associated with myotonia and periodic paralysis. Biophys. J. 72:1204-1219.

22. Hayward, L.J., Sandoval, G.M., and Cannon, S.C. 1999. Defective slow inactivation of sodium channels contributes to familial periodic paralysis. Newrology. 52:1447-1453.

23. Cannon, S.C., Brown, R.H., Jr., and Corey, D.P. 1993. Theoretical reconstruction of myotonia and paralysis caused by incomplete inactivation of sodium channels. Biophys. J. 65:270-288.

24. Hayward, L.J., Brown, R.H., Jr., and Cannon, S.C. 1996. Inactivation defects caused by myotoniaassociated mutations in the sodium channel III-IV linker. J. Gen. Physiol. 107:559-576.

25. Ricker, K., Camacho, L.M., Grafe, P., LehmannHorn, F., and Rudel, R. 1989. Adynamia episodica hereditaria: what causes the weakness? Muscle Nerve. 12:883-891.

26. Venance, S.L., et al. 2006. The primary periodic paralyses: diagnosis, pathogenesis and treatment. Brain. 129:8-17.

27. Fournier, E., et al. 2004. Electromyography guides toward subgroups of mutations in muscle channelopathies. Ann. Neurol. 56:650-661.

28. Fournier, E., et al. 2006. Cold extends electromyography distinction between ion channel mutations causing myotonia. Ann. Neurol. 60:356-365.

29. Spangenburg, E.E., and Booth, F.W. 2003. Molecular regulation of individual skeletal muscle fibre types. Acta Physiol. Scand. 178:413-424.

30. Fluck, M. 2006. Functional, structural and molecular plasticity of mammalian skeletal muscle in response to exercise stimuli. J. Exp. Biol. 209:2239-2248.

31. Bassel-Duby, R., and Olson, E.N. 2006. Signaling pathways in skeletal muscle remodeling. Annu. Rev. Biochem. 75:19-37.

32. Chin, E.R., et al. 1998. A calcineurin-dependent transcriptional pathway controls skeletal muscle fiber type. Genes Dev. 12:2499-2509.

33. Lin, J., et al. 2002. Transcriptional co-activator PGC-1 alpha drives the formation of slow-twitch muscle fibres. Nature. 418:797-801.

34. McClatchey, A.I., et al. 1992. The genomic structure of the human skeletal muscle sodium channel gene. Hum. Mol. Genet. 1:521-527.

35. Hughes, S.M., et al. 1993. Three slow myosin heavy chains sequentially expressed in developing mammalian skeletal muscle. Dev. Biol. 158:183-199.

36. Ruff, R.L., Simoncini, L., and Stuhmer, W. 1988. Slow sodium channel inactivation in mammalian muscle: a possible role in regulating excitability. Muscle Nerve. 11:502-510.

37. Cairns, S.P., Hing, W.A., Slack, J.R., Mills, R.G., and Loiselle, D.S. 1998. Role of extracellular [Ca2+] in fatigue of isolated mammalian skeletal muscle. J. Appl. Physiol. 84:1395-1406.

38. Nielsen, J.J., et al. 2004. Effects of high-intensity intermittent training on potassium kinetics and performance in human skeletal muscle. J. Physiol. 554:857-870

39. Almers, W., Fink, R., and Palade, P.T. 1981. Calcium depletion in frog muscle tubules: the decline of calcium current under maintained depolarization. J. Physiol. 312:177-207.

40. Cannon, S.C., and Strittmatter, S.M. 1993. Functional expression of sodium channel mutations identified in families with periodic paralysis. Neuron. 10:317-326.

41. Gong, B., Miki, T., Seino, S., and Renaud, J.M. 2000 A K(ATP) channel deficiency affects resting tension, not contractile force, during fatigue in skeletal muscle. Am. J. Physiol. Cell Physiol 279:C1351-C1358.

42. Chinnery, P.F., Walls, T.J., Hanna, M.G., Bates, D., and Fawcett, P.R. 2002. Normokalemic periodic paralysis revisited: does it exist? Ann. Neurol. 52:251-252.

43. Poskanzer, D.C., and Kerr, D.N. 1961. A third type of periodic paralysis, with normokalemia and favourable response to sodium chloride. Am.J. Med. 31:328-342.

44. Kelly, P., et al. 1997. Paramyotonia congenita and hyperkalemic periodic paralysis associated with a Met 1592 Val substitution in the skeletal muscle sodium channel alpha subunit - a large kindred with a novel phenotype. Neuromuscul. Disord. 7:105-111.

45. Weber, M.A., et al. 2006. Muscle $\mathrm{Na}+$ channelopathies: MRI detects intracellular $23 \mathrm{Na}$ accumulation during episodic weakness. Neurology. 67:1151-1158.

46. Juel, C., Pilegaard, H., Nielsen, J.J., and Bangsbo, J. 2000. Interstitial $\mathrm{K}(+)$ in human skeletal muscle during and after dynamic graded exercise deter- mined by microdialysis. Am. J. Physiol. Regul. Integr. Comp. Physiol. 278:R400-R406.

47. McArdle, B. 1962. Adynamia episodica hereditaria and its treatment. Brain. 85:121-148.

48. Armstrong, C.M., and Cota, G. 1991. Calcium ion as a cofactor in Na channel gating. Proc. Natl. Acad. Sci.U.S. A. 88:6528-6531.

49. Hille, B., Woodhull, A.M., and Shapiro, B.I. 1975. Negative surface charge near sodium channels of nerve: divalent ions, monovalent ions, and $\mathrm{pH}$. $\mathrm{Phi}$ los. Trans. R. Soc. Lond. B Biol. Sci. 270:301-318.

50. Nielsen, O.B., and Clausen, T. 1997. Regulation of $\mathrm{Na}(+)-\mathrm{K}+$ pump activity in contracting rat muscle. J. Physiol. 503:571-581.

51. Clausen, T. 2003. Na+-K+ pump regulation and skeletal muscle contractility. Physiol. Rev. 83:1269-1324.

52. Clausen, T., Andersen, S.L., and Flatman, J.A. 1993. $\mathrm{Na}(+)-\mathrm{K}+$ pump stimulation elicits recovery of contractility in $\mathrm{K}(+)$-paralysed rat muscle. J. Physiol. 472:521-536.

53. Cairns, S.P., Flatman, J.A., and Clausen, T. 1995. Relation between extracellular $[\mathrm{K}+]$, membrane potential and contraction in rat soleus muscle: modulation by the $\mathrm{Na}+-\mathrm{K}+$ pump. Pflugers Arch. 430:909-915.

54. Macdonald, W.A., Nielsen, O.B., and Clausen, T. 2005. $\mathrm{Na}^{+}-\mathrm{K}+$ pump stimulation restores carbacholine-induced loss of excitability and contractility in rat skeletal muscle. J. Physiol. 563:459-469.

55. Clausen, T., and Overgaard, K. 2000. The role of K+ channels in the force recovery elicited by $\mathrm{Na}^{+-} \mathrm{K}+$ pump stimulation in $\mathrm{Ba} 2+$-paralysed rat skeletal muscle. J. Physiol. 527:325-332.

56. Sejersted, O.M., and Sjogaard, G. 2000. Dynamics and consequences of potassium shifts in skeletal muscle and heart during exercise. Physiol. Rev. 80:1411-1481.

57. McKenna, M.J., Bangsbo, J., and Renaud, J.M. 2008. Muscle $\mathrm{K}+, \mathrm{Na}+, \mathrm{Cl}$ - disturbances and $\mathrm{Na}+, \mathrm{K}+$ pump inactivation: implications for fatigue. J. Appl. Physiol. 104:288-295.

58. Clausen, T., Overgaard, K., and Nielsen, O.B. 2004. Evidence that the $\mathrm{Na}+-\mathrm{K}+$ leak/pump ratio contributes to the difference in endurance between fast- and slow-twitch muscles. Acta Physiol. Scand. 180:209-216.

59. Puigserver, $P$., et al. 1998. A cold-inducible coactivator of nuclear receptors linked to adaptive thermogenesis. Cell. 92:829-839. 